Article

\title{
The Influence of Copper and Silver Nanocolloids on the Quality of Pressed Spring Rapeseed Oil
}

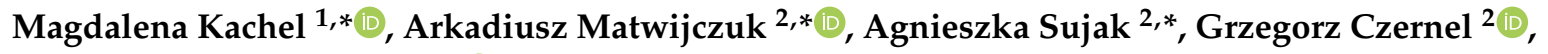 \\ Agnieszka Niemczynowicz ${ }^{3}\left[\right.$ and Aldona Nowicka ${ }^{4}$ \\ 1 Department of Machinery Exploitation and Management of Production Processes, University of Life \\ Sciences in Lublin, Głęboka 28, 20-612 Lublin, Poland \\ 2 Department of Biophysics, University of Life Sciences in Lublin, Akademicka 13, 20-950 Lublin, Poland; \\ grzegorz.czernel@up.lublin.pl \\ 3 Faculty of Mathematics and Computer Science, University of Warmia and Mazury in Olsztyn, Słoneczna 54, \\ 10-710 Olsztyn, Poland; aga.niemczynowicz@gmail.com \\ 4 Analytical Laboratory, Faculty of Chemistry, Maria Curie-Skłodowska University, Maria Curie-Skłodowska \\ Square 3, 20-031 Lublin, Poland; aldona.nowicka@poczta.umcs.lublin.pl \\ * Correspondence: magdalena.kachel@up.lublin.pl (M.K.); arkadiusz.matwijczuk@up.lublin.pl (A.M.); \\ agnieszka.sujak@up.lublin.pl (A.S.)
}

Received: 11 August 2019; Accepted: 9 October 2019; Published: 16 October 2019

\begin{abstract}
The aim of this study was to evaluate the quality of virgin oil pressed from spring rape seeds cultivated with the use of colloidal nanosilver and nanocopper solutions for processing seeds and as foliar fertilizer. The results show that the use of nanometals for seed processing and foliar fertilization increased the content of carotenoid pigments in the oil. The pigment concentration was higher compared to oil pressed from control seeds. The application of nanocolloids onto the seeds and subsequently on the growing plants contributed to the increase of the oxidative stability of oils. Both the acid number (AN) and peroxide number (PN) values were higher in the studied oils as compared to the control, but did not exceed the required allowable levels. Increased content of silver ions and slightly increased copper content was observed in the pressed oil. An infrared spectral analysis (Fourier-Transformed Infra-Red) conducted in combination with chemometrics allowed the classification of the studied oils in terms of their chemical composition. The analysis revealed the presence of bands characteristic of $\mathrm{Cu}-\mathrm{O}-\mathrm{H}$ vibrations after soaking the seeds and spraying the plants with copper nanocolloid, and of C-O-Ag after fertilization with silver nanocolloid.
\end{abstract}

Keywords: nanocolloids; rapeseeds; oil; oxidative stability; carotenoids; ATR-FTIR/PCA analysis

\section{Introduction}

Nanotechnology has revolutionized the conventional food science and food industry. Nanotechnologically enhanced processes of protecting, processing, packaging, and storing food have become commonplace in our food systems [1]. The use of nanotechnological solutions may influence the bioavailability and nutritious value of the produced food [2]. Based on numerous published reports, it can be assumed that the biological properties (including toxicological impact) of nanomaterials are largely dependent on their specific physicochemical parameters [3-5]. Research conducted in the agricultural sector and the continuous advances made in nanotechnology are likely to facilitate and bring about the next stage in the development of high-quality crops, animal products, chemical pesticides, and precision farming techniques. Nanotechnology furthers agricultural sciences and helps to reduce environmental pollution by limiting the production pesticides and chemical fertilizers. Nanoparticle treatment results in alterations of the availability and absorption of mineral 
nutrients by plants [6]. The use of nanoparticles offers a viable alternative to the currently prevalent methods of plant protection [7]. Examples of nano-fertilizers have also been described, which, compared to traditional fertilizers, minimize nutrient losses [8]. The use of nanoparticles in fertilizers facilitates absorption, accelerates plant growth, and increases yields $[9,10]$.

Virgin and cold-pressed oils contain mainly triacylglycerols (approximately $95 \%$ ) and a relatively small content of diacylglycerols, monoacylglycerols, and free fatty acids, including compound groups such as phospholipids, tocopherols and tocotrienols, free and esterified sterols, hydrocarbons (squalene), triterpene alcohols, carotenoids, chlorophylls and other pigments, which constitute highly valued nutritional ingredients [11-13]. The inclusion of carotenoids in human diet reduces the content of lipid peroxides in blood plasma, which helps to prevent diseases caused by ROS (reactive oxygen species). Among other benefits, carotenoids reduce the risk of cardiac infraction, stroke, myocardial ischemia, cataract, age-related macular degeneration, Alzheimer's disease, cancer, and other age-related degenerative diseases [14].

Eating food containing oxidized lipids may facilitate the formation of reactive oxygen species and free radicals, which in turn may lead to the oxidation of biological membranes and increased mutagenic, genotoxic, and angiotoxic potential. The same can also contribute to the development of cardiovascular disorders [15]. The process of oxidation is influenced by numerous factors including the availability of oxygen, temperature, heavy metals and metal ions $\left(\mathrm{Ca}^{2+}\right.$ and $\left.\mathrm{Fe}^{3+}\right)$, exposure to light and various chemical factors facilitating the initiation of oxidizing processes $[16,17]$. The above factors may facilitate the formation of free radicals which results in the emergence of peroxide radicals, hydroperoxides, and subsequent chain reactions leading to the presence of secondary oxidation products such as aldehydes, ketones and more single chain unsaturated lipids and triglycerides that can contribute to the oxidative stress in the cells and especially in the chloroplasts [18].

In the presence of light, chlorophylls and their derivatives are the most active promoters of oxidation processes in olive oil and virgin oils, and therefore significantly influence their oxidative susceptibility [19]. The effects of exposing olive oil and virgin oils to light at temperatures ranging from $2{ }^{\circ} \mathrm{C}$ to $40{ }^{\circ} \mathrm{C}$ have been analyzed in detail [20]. The authors demonstrated the great impact of the intensity of fluorescent light on the rate of oxidation.

Since no reports have been found on the effect of application of metal nanocolloids (Ag and $\mathrm{Cu}$ ) on oleaginous plants or on the products obtained from processing seeds, the presented study aimed to analyze rapeseed virgin pressed oils and evaluate their quality by measuring the following parameters: (1) content of pigments, i.e., chlorophyll $a$ and $b$, carotenoids, and an assessment of the oil color; (2) acid number (AN), peroxide number (PN), and oxidative stability; (3) metal content ( $\mathrm{Ag}, \mathrm{Cu}, \mathrm{Fe}$, and $\mathrm{Mn}$ ) in the oils; and (4) qualitative analysis using the technique of ATR-FTIR spectroscopy.

\section{Materials and Methods}

\subsection{Origin of Plants and Nanoparticles}

The test material consisted of a variety of spring oilseed rape (Brassica napus L. var. arvensis) "Feliks" cultivar, from the agricultural station Hodowla Roślin Strzelce Sp. z o.o. Group IHAR.

Nanomaterials used in laboratory and field tests included two commercially available agents supplied in $1.0 \mathrm{dm}^{3}$ bottles containing silver nanocolloid and copper nanocolloid concentrated at $\geq 0.1 \%$ silver (ITP- $1 \mathrm{KAg}$ PO) and $\geq 0.1 \%$ copper (ITP- $1 \mathrm{KCu}$ PO), produced by ITP-SYSTEM Sp. $z$ o.o. in Dąbrowa Górnicza.

\subsection{Preparation of Nanocolloid Solutions}

The nanosilver and nanocopper colloidal solutions were applied using a $50 \mathrm{~mL}$ commercial suspension made up to $1000 \mathrm{~mL}$ with sterile distilled water (SDW). In this way, nanocolloid suspensions with concentrations of about $0.01 \%$ of silver nanoparticles and $0.005 \%$ of cooper nanoparticles were obtained. 


\subsection{Scanning Electron Microscopy (SEM)}

The size and morphology of silver and copper nanocolloids were determined using SEM. After washing in double distilled water and ultrasonication, samples were placed on circular aluminum stubs, skin-dried and transferred into the chamber of a Quanta 3D FEG (FEI) scanning electron microscope. Micrographs were taken with an ETD detector, at the accelerating voltage of $30 \mathrm{kV}$. The AgNC and CuNC diameter was measured with Nis-Elements Advanced Research software. Particle 104 distribution was derived from a histogram for 300 particles.

\subsection{Rape Cultivation in a Field Experiment}

The field experiment (split-plot method, in three replicates) was conducted in a two-year cycle during 2016-2017, on average grade, sandy grain soil. At the beginning of experiment, the soil's abundance in nutrients was: $\mathrm{K}_{2} \mathrm{O} 19.3 \mathrm{mg} \cdot 100 \mathrm{~g}^{-1}$ soil; $\mathrm{P}_{2} \mathrm{O}_{5} 19.0 \mathrm{mg} \cdot 100 \mathrm{~g}^{-1}$ soil; $\mathrm{Mg} 6.4 \mathrm{mg} \cdot 100 \mathrm{~g}^{-1}$ soil; B $0.61 \mathrm{mg} \cdot 1 \mathrm{~kg}^{-1}$ soil; Mn $198.1 \mathrm{mg} \cdot 1 \mathrm{~kg}^{-1}$ soil; Cu $1.51 \mathrm{mg} \cdot 1 \mathrm{~kg}^{-1}$ soil; Zn $12.58 \mathrm{mg} \cdot 1 \mathrm{~kg}^{-1}$ soil; Fe $925 \mathrm{mg} \cdot 1 \mathrm{~kg}^{-1}$ soil; and Mo $0.022 \mathrm{mg} \cdot 1 \mathrm{~kg}^{-1}$ soil. Mineral fertilization was $35 \mathrm{~kg}$ P and $66.5 \mathrm{~kg} \mathrm{~K} \cdot \mathrm{ha}^{-1}$ used in spring before sowing and before vegetation start in the subsequent years of cultivation.

Before sowing, the seeds were divided into three groups: non-soaked in the prepared nanocolloidal solutions, soaked in silver nanocolloid solution, and soaked in copper nanocolloid solution. The $30 \mathrm{~m}^{2}$ plots were established at the experimental farm of the University of life sciences in Lublin located in Czesłowice, Lubelskie Voivodship, eastern Poland.

Two groups of rapeseeds were soaked (processed) for $1 \mathrm{~h}$ in the prepared colloidal solutions of nanosilver or nanocopper (ITP-2KAg PO and ITP-1KCu PO), skin-dried (in natural conditions, agitated every $3 \mathrm{~h}$ ) in a thin, $1 \mathrm{~cm}$ layer inside plastic 20-L containers to prepare them for sowing. The control sample comprised non-processed seeds. The prepared material (seeds) was subsequently divided into five experimental variant groups:

- Variant I: Non-pelleted seeds sown in the soil and subsequently sprayed during the florescence stage (61-66 BBCH) with the colloidal silver solution-(O)AgNC dosed at $50 \mathrm{~cm}^{3} \cdot \mathrm{L}^{-1}$.

- Variant II: Non-pelleted seeds sown in the ground and subsequently sprayed during the florescence stage (61-66 BBCH) with the colloidal nanocopper solution (O)CuNC concentrated at $50 \mathrm{~cm}^{3} \cdot \mathrm{L}^{-1}$.

- Variant III: Non-pelleted seeds soaked in the colloidal nanocopper solution (N/O)CuNC dosed at $50 \mathrm{~cm}^{3} \cdot \mathrm{dm}^{-3}$ before sowing, and subsequently sprayed during the florescence stage (61-66 $\left.\mathrm{BBCH}\right)$ with the colloidal nanocopper solution (N/O)CuNC dosed at $50 \mathrm{~cm}^{3} \cdot \mathrm{L}^{-1}$.

- Variant IV: Non-pelleted seeds soaked in the colloidal nanosilver solution (N/O)AgNC dosed at $50 \mathrm{~cm}^{3} \cdot \mathrm{dm}^{-3}$ before sowing, and subsequently sprayed during the florescence stage (61-66 BBCH) with the colloidal nanosilver solution (N/O)AgNC dosed at $50 \mathrm{~cm}^{3} \cdot \mathrm{L}^{-1}$.

- Variant V: Control sample, non-pelleted seeds that were not soaked in a nanocolloidal solution or sprayed with a nanocopper or nanosilver solution during cultivation.

The adopted dosage of nanocolloids in the field experiment was $50 \mathrm{~cm}^{3} \cdot \mathrm{L}^{-1}$. The dosage was selected to minimize the risk of potential adverse effects on the natural environment.

\subsection{Oil Pressing}

Rapeseed oil was pressed using an expeller with a replaceable nozzle of $8 \mathrm{~mm}$ in diameter connected to a continuous sieve system from Farmet DUO. Before operation, the expeller was heated up to $50^{\circ} \mathrm{C}$. Once the press was engaged and stable pressing temperature was reached, the process proper could commence. The temperature was stabilized at approximately $60^{\circ} \mathrm{C}$ by pre-pressing oil from roughly $1 \mathrm{~kg}$ of seeds. The pressing temperature was measured using an AD 20TH digital thermometer from Amarell-ama-digit. After pressing, the oil was stored in $200 \mathrm{~cm}^{3}$ dark glass bottles at $5{ }^{\circ} \mathrm{C}$ to allow natural separation over six days, and subsequently decanted and submitted for further analyses. 


\subsection{Measurement of the Acid Number (AN)}

The measurement of the acid number (AN) was conducted in accordance with the applicable PN-EN ISO 660:2005 [21] standard. The method entails neutralization of free fatty acids present in the sample with a $\mathrm{KOH}$ solution. The results were expressed in $\mathrm{mg} \mathrm{KOH} \cdot \mathrm{g}^{-1}$ and estimated as a triplicate average.

\subsection{Measurement of the Peroxide Number (PN)}

The measurement of the peroxide number $(\mathrm{PN})$ was conducted in accordance with the applicable PN-EN ISO 3960:2012 [22] standard. It entailed the quantitative determination of iodine released from potassium iodide under the influence of peroxides present in the analyzed fat. The results were expressed as $\mathrm{mmolO} \cdot \mathrm{kg}^{-1}$ and estimated as a triplicate average.

\subsection{Measurement of Oxidative Stability}

Oxidative stability was measured with the use of a Rancimat 670 device (Metrohm AG, Herisau, Switzerland). Oil samples (2.5 g) were measured out into reaction dishes and heated at $120^{\circ} \mathrm{C}$ in a $20 \mathrm{dm}^{3} \cdot \mathrm{h}^{-1}$ jet of hot air, in accordance with the applicable PN-EN ISO 6886:2009 [23] standard. The time required to reach the conductivity inflection point was registered as induction time (IT) and expressed in hours. Normal time was determined on the basis of the induction time using the validation index calculated for the induction time relative to sample temperature. Normal time was calculated using StabNet software controlling the Rancimat device.

\subsection{Measurement of Pigment Content in Oil}

The measurement of chlorophyll $a$, chlorophyll $b$, and carotenoid concentrations in the pressed oil samples were performed with the spectrophotometric method using a bi-compound Jasco V-630 spectrophotometer with a UV-VIS radiation beam. The method of establishing the pigment content entailed 20-fold dilution of the oil samples in acetone, after which their absorption spectra were measured within the range of $350-750 \mathrm{~nm}$. The results were expressed in $\mu \mathrm{g} \cdot \mathrm{mL}^{-1}$ and estimated as triplicate average in accordance with the Lichtenthaler and Buschmann method [24].

\subsection{Measurement of Oil Color}

The colorimetric measurements were performed using a CR-221 Chroma meter (Minolta, Osaka, Japan) with $45^{\circ}$ perimeter illumination and $0^{\circ}$ viewing angle measurement geometry. A pulsed xenon lamp $\left(\mathrm{D}_{65}-6504 \mathrm{~K}\right)$ was used as the light source. The measuring area diameter amounted to $3 \mathrm{~mm}$. Measurements were conducted in CIE Lab color measuring mode (CIE $\mathrm{L}^{*} \mathrm{a}^{*} \mathrm{~b}^{*}$ ) [25]. The three coordinates of the CIE Lab color evaluation system represent $\mathrm{L}^{*}$ for brightness ( 0 for black and 100 for white), $a^{*}$ for red-green scale chromaticity (negative values for green and positive values for magenta) and $b^{*}$ for blue-yellow scale chromaticity (negative values for blue and positive values for yellow). The instrument was calibrated for a white ceramic plate (CIE $L^{*}=99.25, a^{*}=0.60$, $\mathrm{b}^{*}=1.87$ ). Before the analysis, samples were allowed to equilibrate for $2 \mathrm{~h}$ at room temperature. The standard $10 \mathrm{~mm}$ polypropylene cuvettes were filled with $4 \mathrm{~cm}^{3}$ of the samples. The cuvettes were covered with cardboard from three sides (whiteness ${ }^{* * * *}$ ), except the side directed towards the measuring head, to provide a white background. The measurements were carried out in a darkened room to exclude interference from external light sources. To ensure reproducibility of the instrument measurement, $L^{*} a^{*} b^{*}$ color coordinates were recorded in at least triplicate for each sample and averaged. Background measurements were made under identical conditions using a cuvette filled with distilled water. The following color parameters were calculated from the obtained CIE Lab coordinates: h (hue angle), Chroma $\left(\mathrm{C}^{*}\right)$, and distance from the background $(\Delta \mathrm{H})$, where:

$$
h=\arctan \left(\frac{\mathrm{b} *}{\mathrm{a} *}\right)
$$




$$
\begin{gathered}
\mathrm{C}^{*}=\sqrt{\mathrm{a}^{* 2}+\mathrm{b}^{* 2}} \\
\Delta \mathrm{H}=\sqrt{\left(\mathrm{L}_{1}^{*}-\mathrm{L}_{2}^{*}\right)^{2}+\left(\mathrm{a}_{1}^{*}-\mathrm{aL}_{2}^{*}\right)^{2}+\left(\mathrm{b}_{1}^{*}-\mathrm{bL}_{2}^{*}\right)^{2}}
\end{gathered}
$$

Indices 1 and 2 refer to sample and background, respectively.

\subsection{Measurement of Metal Content}

Oils of $500 \pm 1 \mathrm{mg}$ portions were poured with $5 \mathrm{~mL}$ of concentrated $\mathrm{HNO}_{3}$ (Sigma Aldrich, Steinheim, Germany) and wet-ashed. Samples were mineralized in Teflon vials (DAP 100 type) using the Microwave Digestion System (Berghof Speedwave, Eningen, Germany) with optical temperature and pressure monitoring of each individual sample during acid digestion. Mineralization was performed in the following steps: (1) $15 \mathrm{~min}$ raising temperature from room to $140{ }^{\circ} \mathrm{C}$; (2) $5 \mathrm{~min}$ at $140{ }^{\circ} \mathrm{C}$; (3) $5 \mathrm{~min}$ raising temperature from $140{ }^{\circ} \mathrm{C}$ to $170{ }^{\circ} \mathrm{C}$; (4) $15 \mathrm{~min}$ at $170{ }^{\circ} \mathrm{C}$; and (4) cooling to room temperature (variable time). The pressure level during mineralization did not exceed 12 bar. After this process, clear solution of elements was cooled to room temperature, transferred to a 50 -mL volumetric flask and poured with demineralized water (ELGA Pure Lab Classic) to the indicated level. To determine concentrations of particular elements, Inductively Coupled Plasma Optical Emission Spectrometer (ICP-OES; Thermo Fisher Scientific iCAP Series 6500, Fremont, CA, USA) equipped with a charge injection device (CID) detector and controlled with iTEVA software was used. Standard parameters, as previously published by Sujak et al. [26], were set. Multi-element stock solutions (Inorganic Ventures) were used as standards.

Analyses were run on all oil samples and additionally on a blank sample $\left(5 \% \mathrm{HNO}_{3}\right)$. To control the accuracy of the method under existing working conditions, a certified reference material, TraceCERT-Periodic table mix 1 for ICP (Fluka Analytical, Sigma Aldrich Steinheim, Germany), was used. To calculate the recovery percentage, three randomly selected samples were supplied with known amounts of the analytical standard. The analytical procedure was checked using Quality Control Standard 28 (IV-28) from Inorganic Ventures.

\subsection{Measurement of ATR-FTIR Spectra}

The measurements of the infrared spectra for the analyzed oils were conducted using a Vertex 70 FTIR spectrometer (by Varian). The device's ATR (attenuated total reflection) extension utilizes a ZnSe crystal of the appropriate geometry (cut at $45^{\circ}$ ) to allow twentyfold internal bounce of the absorbed bean. During the test, 16 measurement scans were registered; the spectra were subsequently averaged by software. Before the measurement, the $\mathrm{ZnSe}$ crystal was cleaned using ultra-clean solvents by Sigma-Aldrich. Prior to the measurement $(1 \mathrm{~h})$ and during the entire analysis, a neutral $\mathrm{N}_{2}$ atmosphere was maintained inside the measurement chamber. Spectral measurements were taken within the range of $4000-500 \mathrm{~cm}^{-1}$ at the resolution of $2 \mathrm{~cm}^{-1}$. Spectral analysis and result processing was conducted using Grams/AI software by ThermoGalactic Industries (Salem, MA, USA). All spectra were measured at $23^{\circ} \mathrm{C}$.

\subsection{Statistical Analysis}

The obtained results were analyzed statistically. For all variables, the mean values and standard deviations were calculated, and the post hoc Tukey's test (HSD) as well as correlation matrices were performed. The analysis was conducted at the significance level of $p<0.05$. The results are presented as $n=9$ means \pm SD. The calculations were performed using Statistica 10 software from Statsoft.

\subsection{Hierarchical Cluster Analysis (HCA)}

Cluster Analysis (CA) is a method for dividing a group of objects into classes, so that similar objects are in the same class. We assumed that the groups are not known before the mathematical 
analysis and no assumptions were made about the distribution of the variables. Therefore, CA was used to identify objects located closely together in the variable space.

Hierarchical Cluster Analysis (HCA) is a cluster analysis method that seeks to build a hierarchy of clusters. We can use any valid metric as a measure of similarity between pairs of observations. It means that the samples in the same clusters show many similarities, whereas samples in different clusters are dissimilar [27].

In the present study, we applied HCA to Euclidean distance between considered FTIR spectra of oils samples. To establish the distance matrix for samples under cluster analysis, absorbencies were selected as a measure for the cluster analysis in FTIR. The hierarchical cluster analysis and dendrogram were performed with Stastistica 13 software.

\subsection{Similarity Evaluation}

To obtain the cosine between the orientation of two IR spectra, where $x_{i}$ and $y_{i}$ are the $i$-th elements in two different fingerprints, $x$ and $y$, respectively, we can using the congruence or correlation coefficients in the following formulas, respectively $[28,29]$ :

$$
\begin{gathered}
r_{\text {con }}=\frac{\sum_{i=1}^{\text {num }} x_{i} y_{i}}{\sqrt{\sum_{i=1}^{\text {num }} x_{i}^{2} \cdot \sum_{i=1}^{\text {num }} y_{i}^{2}}} \\
r_{\text {cor }}=\frac{\sum_{i=1}^{\text {num }}\left(x_{i}-\bar{x}\right)\left(y_{i}-\bar{y}\right)}{\sqrt{\sum_{i=1}^{\text {num }}\left(x_{i}-\bar{x}\right)^{2} \cdot \sum_{i=1}^{\text {num }}\left(y_{i}-\bar{y}\right)^{2}}}
\end{gathered}
$$

where $\bar{x}=\sum_{i=1}^{n u m} \frac{1}{n} x_{i}, \bar{y}=\sum_{i=1}^{n u m} \frac{1}{n} y_{i}$ and num denotes the number of FTIR data. For standardized fingerprints, both coefficients give the same results.

\subsection{Principal Component Analysis (PCA)}

The PCA was based on the data array of the fingerprints of the FTIR spectra of each analyzed sample. The first several scores of the PCA results were used to make a projection plot that provided a visual determination of the similarity between the respective fingerprints of FTIR spectra. Origin Pro software (Origin Lab, Northampton, MA, USA) was used for the purposes of PCA in this study.

\section{Results}

The size of nanoparticles in the nanocolloid solutions used for the study was measured with the use of scanning electron microscopy (Figure 1). The estimated sizes were $13.3 \pm 3.6$ and $38.3 \pm 10.9 \mathrm{~nm}$ for AgNC (Figure 1A) and CuNC (Figure 1B), respectively. To ensure a high level of dispersion of the analyzed nanoparticles, the colloid samples were treated with ultrasound prior to the measurement. In the case of silver nanoparticles, the visualization showed nanoparticles with a clear granular structure, without visible areas containing nanoparticle agglomerates. Despite using similar methods, in the case of copper nanoparticles, complete deagglomeration of the sample was not achieved. The same suggests that the nanoparticle size obtained in the SEM experiment may have been somewhat overestimated due to charges and coating on particle surfaces [30].

Table 1 presents the carotenoids and chlorophyll $a$ and $b$ content in the oil pressed from rapeseeds harvested from plants grown after pre-soaking the seeds before sowing and spraying the plants with the use of nanosilver and nanocopper colloid solutions (AgNC and CuNC). The pigment content in the analyzed samples from both years of the field experiment (2016 and 2017) was higher than that observed in the control. In 2016, chlorophyll $a$ ( $\mathrm{chl} a$ ) content in the oil from the control sample was $7.72 \mu \mathrm{g} \cdot \mathrm{mL}^{-1}$, chlorophyll $b$ ( $\mathrm{chl} b$ ) was $3.36 \mu \mathrm{g} \cdot \mathrm{mL}^{-1}$, and carotenoids (car) was $80.45 \mu \mathrm{g} \cdot \mathrm{mL}^{-1}$. Spraying the plants with $(\mathrm{O}) \mathrm{AgNC}$ and $(\mathrm{O}) \mathrm{CuNC}$ nanocolloids resulted in a significant increase in the content of both chl $a$ and $\mathrm{chl} b$ relative to the control. The respective increase was, respectively, 
$13.0 \%$ and $43.75 \%$ after the application of silver nanocolloid. After spraying the plants with copper nanocolloid $(\mathrm{O}) \mathrm{CuNC}$, the respective values increased by $21.24 \%$ and $37.79 \%$. In the case of carotenoid content after single application, i.e., only spraying the plants with the nanocolloids, a significant decrease of the values, by $7.29 \%$ and $9.58 \%$, was observed relative to the control. For plants grown from seeds soaked and sprayed with (N/O) AgNC nanocolloid, the total chlorophyll $a$ and $b$ content in oil was $13.36 \mu \mathrm{g} \cdot \mathrm{mL}^{-1}$, which was statistically significantly higher relative to the control—by $11.14 \%$ in the case of chlorophyll $a$ and $42.3 \%$ in the case of chlorophyll $b$. The carotenoid content in the analyzed oil was $2.67 \%$ lower than in the control. A similar correlation was observed in the case of copper nanocolloid applied in the (N/O) CuNC variant. The total chlorophyll content in the oil under this variant was $15.10 \mu \mathrm{g} \cdot \mathrm{mL}^{-1}$ and both chlorophyll levels were higher after application of nanocolloid at the concentration of $0.005 \%$ or $0.01 \%$ as compared to the control. The increase was statistically significant-21.11\% (for chl $a$ ) and $71.13 \%$ (for $\operatorname{chl} b$ ).
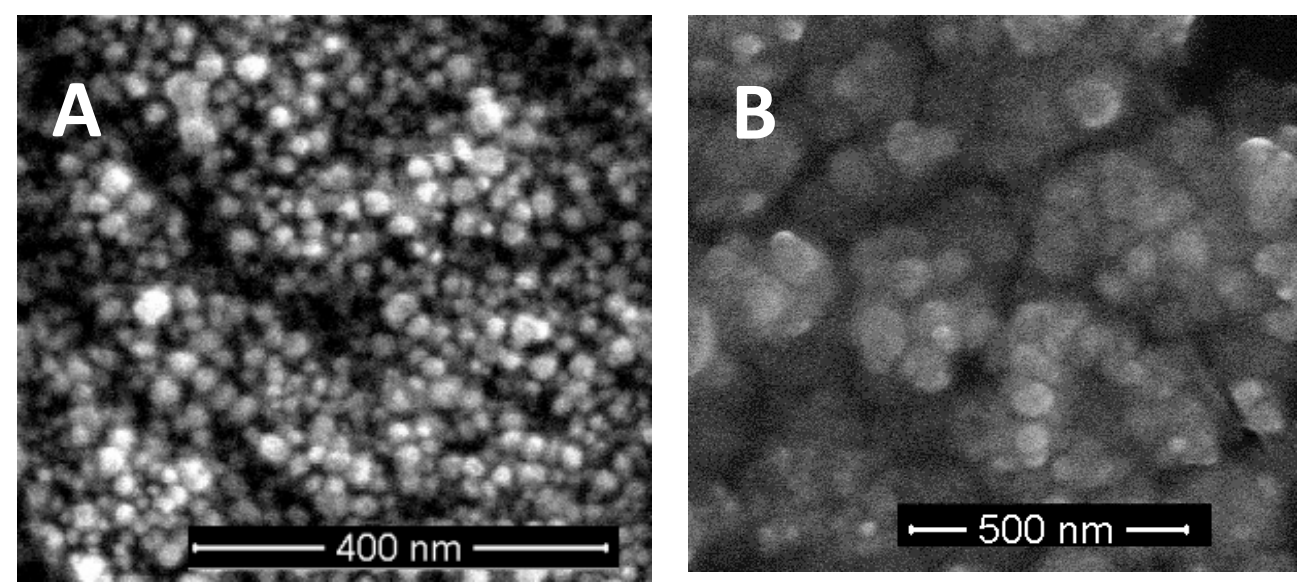

Figure 1. Micrographs of (A) AgNC and (B) CuNC on the right, magnified 100,000×.

Table 1. Chlorophyll and carotenoid content in virgin rapeseed oil.

\begin{tabular}{cccccccc}
\hline Year & Pigment & Unit & Control & (O) AgNC & (O) CuNC & (N/O) AgNC & (N/O) CuNC \\
\hline \multirow{2}{*}{2016} & chlorophyll $a$ & & $7.72 \pm 0.91 \mathrm{~A}$ & $8.73 \pm 0.75 \mathrm{aB}$ & $9.36 \pm 0.78 \mathrm{aB}$ & $8.58 \pm 0.82 \mathrm{AB}$ & $9.35 \pm 0.32 \mathrm{aB}$ \\
& chlorophyll $b$ & $\mu \mathrm{g} \cdot \mathrm{mL}^{-1}$ & $3.36 \pm 0.90 \mathrm{~A}$ & $4.83 \pm 0.44 \mathrm{aB}$ & $4.63 \pm 0.44 \mathrm{aB}$ & $4.78 \pm 0.41 \mathrm{aB}$ & $5.75 \pm 0.43 \mathrm{aC}$ \\
& carotenoids & & $80.45 \pm 6.32 \mathrm{~A}$ & $74.58 \pm 5.45 \mathrm{aB}$ & $72.74 \pm 5.34 \mathrm{aB}$ & $82.60 \pm 5.82 \mathrm{aA}$ & $85.76 \pm 4.24 \mathrm{aA}$ \\
\hline \multirow{2}{*}{2017} & chlorophyll $a$ & & $7.85 \pm 0.87 \mathrm{~A}$ & $7.81 \pm 0.23 \mathrm{~A}$ & $8.99 \pm 0.45 \mathrm{aB}$ & $7.47 \pm 0.22 \mathrm{~A}$ & $9.90 \pm 0.21 \mathrm{aB}$ \\
& chlorophyll $b$ & $\mu \mathrm{g} \cdot \mathrm{mL}^{-1}$ & $3.24 \pm 0.23 \mathrm{~A}$ & $3.74 \pm 0.15 \mathrm{~A}$ & $4.57 \pm 0.12 \mathrm{aB}$ & $4.39 \pm 0.23 \mathrm{aB}$ & $4.35 \pm 0.34 \mathrm{aB}$ \\
& carotenoids & & $78.59 \pm 4.13 \mathrm{~A}$ & $80.83 \pm 4.23 \mathrm{aB}$ & $77.45 \pm 3.26 \mathrm{aC}$ & $77.49 \pm 4.31 \mathrm{aC}$ & $80.10 \pm 4.21 \mathrm{aB}$ \\
\hline
\end{tabular}

a-b, statistically significant cultivar differences relative to the control; A-C, statistically significant differences between samples under the same field experiment; mean values marked with the same letter are not statistically significantly different $(p>0.05)$.

Application of $0.01 \%$ silver nanoparticles and the $0.005 \%$ of cooper nanoparticles to the seeds and growing plants was positively $\left(R^{2}=0.53\right)$ and strongly $\left(R^{2}=0.76\right)$ correlated, at the significance level of $p<0.05$, with the content of chlorophyll $a$ and $b$ in rapeseed oil.

In 2017, the pigment content was also relatively high at the levels of, respectively, $7.85 \mu \mathrm{g} \cdot \mathrm{mL}^{-1}$ (chl a), $3.24 \mu \mathrm{g} \cdot \mathrm{mL}^{-1}$ (chl $b$ ), and $78.59 \mu \mathrm{g} \cdot \mathrm{mL}^{-1}$ (car). After soaking the seeds and spraying the plants in the $(\mathrm{N} / \mathrm{O})$ AgNC sample, the total chlorophyll level was $11.86 \mu \mathrm{g} \cdot \mathrm{mL}^{-1}$. This value was statistically significant relative to the control only in the case of chl $b$, where the increase of $35.50 \%$ was observed, and carotenoids, which increased by $10.30 \%$. After the application in (N/O)CuNC, we observed a significant increase with respect to all the analyzed parameters by, respectively, $26.11 \%(\operatorname{chl} a), 34.25 \%$ (chl b), and 2\% (car) (Table 1.).

Application of nano-colloids to the seeds and growing plants was positively $\left(R^{2}=0.67\right)$ correlated, only with the content of chlorophyll $b$ in oils at the significance level of $p<0.05$. 
The $L^{*}, a^{*}$ and $b^{*}$ color parameters for oil pressed from rapeseeds grown during 2016-2017 are presented in Table 2. Oil samples from 2016 were relatively dark as indicated by the low value of $\mathrm{L}^{*}$ (relative sample brightness) - from 5.28 in the oil under the (N/O) AgNC variant to 7.96 in the control. The application of $\mathrm{Ag}$ and $\mathrm{Cu}$ nanocolloids contributed to the reduction of the $\mathrm{L}^{*}$ parameter in all variants of the experiment, although statistical differences were found only after twofold (N/O) AgNC application, both relative to the control and other experimental variants. Positive $\mathrm{a}^{*}$ values (between 3.96 in (N/O) AgNC oil and 4.67 in $(\mathrm{O}) \mathrm{CuNC}$ oil) indicate admixture of the red tint in the general yellow color of oils (positive values of parameter $b^{*}$ : between 6.45 and 11.07). A statistically significant reduction in the $\mathrm{a}^{*}$ parameter relative to the control was observed in $(\mathrm{N} / \mathrm{O}) \mathrm{AgNC}$ (twofold application of Ag nanocolloid). No statistical differences were found between the experimental variants. In the case of parameter $\mathrm{b}^{*}$, a statistically significant decrease in its value was observed in all cases after the application of nano- $\mathrm{Ag}$ and $-\mathrm{Cu}$, as compared to the control. In the case of the (N/O) AgNC experimental variant, a statistically significant decrease in parameter $b^{*}$ was observed compared to other variants of the nanocolloid application. No statistical differences between oils were found in the case of hue angle $h$ (values between 1.02 and 1.17). A statistically significant decrease of chroma $C^{*}$ was observed for all variants treated with nanocolloid as compared to the control. The largest decrease of this parameter was observed in $(\mathrm{N} / \mathrm{O}) \mathrm{AgNC}(37.05 \%)$ and $(\mathrm{O}) \mathrm{AgNC}(14.65 \%)$ experimental variants. This indicates that the colors became less pure. The highest distance from background $\Delta \mathrm{H}$ in the case of control oil (14.87) indicates that it has the most intensive color, which statistically significantly differs from the color of other oils. This value for oil obtained from seeds under the (N/O) AgNC experimental variant was lower than the value obtained in the control by $22.19 \%(11.57)$, and in the case of the $(\mathrm{N} / \mathrm{O})$ CuNC by $22.39 \%$ (11.54).

Table 2. Analysis of color parameters of virgin rapeseed oil.

\begin{tabular}{cccccc}
\hline \multirow{2}{*}{ Color Parameters } & \multicolumn{5}{c}{$\mathbf{2 0 1 6}$} \\
\cline { 2 - 6 } & Control & $\mathbf{( O )} \mathbf{A g N C}$ & $\mathbf{( O )} \mathbf{C u N C}$ & $\mathbf{( N / O ) ~ A g N C}$ & (N/O) CuNC \\
\hline $\mathrm{L}^{*}$ & $7.96 \pm 0.15 \mathrm{~A}$ & $7.48 \pm 0.15 \mathrm{~A}$ & $7.21 \pm 0.19 \mathrm{~A}$ & $5.28 \pm 0.19 \mathrm{aB}$ & $7.30 \pm 0.08 \mathrm{~A}$ \\
$\mathrm{a}^{*}$ & $4.66 \pm 0.12 \mathrm{~A}$ & $4.51 \pm 0.20 \mathrm{~A}$ & $4.67 \pm 0.20 \mathrm{~A}$ & $3.96 \pm 0.14 \mathrm{aA}$ & $4.10 \pm 0.22 \mathrm{~A}$ \\
$\mathrm{~b}^{*}$ & $11.07 \pm 0.29 \mathrm{~A}$ & $9.21 \pm 0.29 \mathrm{aB}$ & $9.55 \pm 0.36 \mathrm{aB}$ & $6.45 \pm 0.31 \mathrm{aC}$ & $9.62 \pm 0.30 \mathrm{aAB}$ \\
$\mathrm{h}$ & $1.17 \pm 0.01 \mathrm{~A}$ & $1.1 \pm 0.01 \mathrm{~A}$ & $1.12 \pm 0.01 \mathrm{~A}$ & $1.02 \pm 0.01 \mathrm{~A}$ & $1.17 \pm 0.02 \mathrm{~A}$ \\
Chroma $\mathrm{C}^{*}$ & $12.01 \pm 0.01 \mathrm{~A}$ & $10.25 \pm 0.01 \mathrm{aB}$ & $10.64 \pm 0.034 \mathrm{aB}$ & $7.56 \pm 0.32 \mathrm{aC}$ & $10.46 \pm 0.34 \mathrm{aB}$ \\
$\Delta \mathrm{H}$ & $14.87 \pm 0.02 \mathrm{~A}$ & $13.81 \pm 0.37 \mathrm{aB}$ & $13.58 \pm 0.37 \mathrm{~B}$ & $11.57 \pm 1.67 \mathrm{aC}$ & $11.54 \pm 1.40 \mathrm{aC}$ \\
\hline & & \multicolumn{3}{c}{} \\
\hline $\mathrm{L}^{*}$ & $8.39 \pm 0.18 \mathrm{~A}$ & $5.07 \pm 0.05 \mathrm{a}$ & $2.12 \pm 0.03 \mathrm{aC}$ & $2.38 \pm 0.04 \mathrm{aC}$ & $2.82 \pm 0.03 \mathrm{aC}$ \\
$\mathrm{a}^{*}$ & $4.40 \pm 0.19 \mathrm{~A}$ & $3.43 \pm 0.12 \mathrm{aB}$ & $3.41 \pm 0.08 \mathrm{aB}$ & $3.38 \pm 0.11 \mathrm{aB}$ & $3.26 \pm 0.14 \mathrm{aB}$ \\
$\mathrm{b}^{*}$ & $8.74 \pm 0.31 \mathrm{~A}$ & $5.91 \pm 0.13 \mathrm{aB}$ & $0.99 \pm 0.04 \mathrm{aC}$ & $0.84 \pm 0.06 \mathrm{aC}$ & $2.22 \pm 0.06 \mathrm{aD}$ \\
$\mathrm{h}$ & $1.11 \pm 0.01 \mathrm{~A}$ & $1.04 \pm 0.01 \mathrm{~A}$ & $0.28 \pm 0.01 \mathrm{~A}$ & $0.24 \pm 0.02 \mathrm{~A}$ & $0.59 \pm 0.02 \mathrm{~A}$ \\
Chroma C* & $9.83 \pm 0.34 \mathrm{~A}$ & $6.83 \pm 0.15 \mathrm{aB}$ & $3.55 \pm 0.01 \mathrm{aC}$ & $3.49 \pm 0.11 \mathrm{aD}$ & $3.94 \pm 0.14 \mathrm{aD}$ \\
$\Delta \mathrm{H}$ & $12.92 \pm 0.31 \mathrm{~A}$ & $12.16 \pm 0.07 \mathrm{~A}$ & $12.11 \pm 0.03 \mathrm{~A}$ & $11.75 \pm 0.02 \mathrm{a} \mathrm{A}$ & $11.82 \pm 0.04 \mathrm{aA}$ \\
\hline
\end{tabular}

a, statistically significant cultivar differences relative to the control; A-D, statistically significant differences between samples under the same field experiment; mean values marked with the same letter are not statistically significantly different $(p>0.05)$.

$\mathrm{L}^{*}$ values for the samples from 2017 indicated fairly dark colors (from 2.12 for $(\mathrm{O}) \mathrm{CuNC}$ to 8.39 for control). The control oil was slightly brighter compared to the control from the previous year (no statistical differences). Interestingly, the application of nanocolloids resulted in a greater reduction of $\mathrm{L}^{*}$ compared to the control than in the previous year (maximally $6.27 \mathrm{~L}^{*}$ units in the case of $(\mathrm{N} / \mathrm{O})$ $\mathrm{CuNC}$ oil, 2.68 in the previous year for the (N/O) AgNC sample). The $\mathrm{a}^{*}$ parameter ranged between 3.26 for $(\mathrm{N} / \mathrm{O}) \mathrm{CuNC}$ oil and 4.40 for the control, whereas the values of $\mathrm{b}^{*}$ ranged from 0.84 for $(\mathrm{N} / \mathrm{O})$ AgNC to 8.74 for the control oil. A statistically significant decrease of these parameters in the analyzed oils was observed for all variants of the experiment, as compared to the control sample.

Although no statistical differences were found, one can observe a decrease of the hue angle value. 
Similar to 2016, $\Delta \mathrm{H}$ indicates that the 2017 control oil had the most intense color and statistically significantly differed in color from oils obtained after the double application of either nanocolloid.

The adopted primary factors describing the oil's stability included the acid number (AN), peroxide number (PN), and oxidative stability (Table 3). In 2016, the control oxidative stability was $5.72 \mathrm{~h}$ for the induction time, and $25.48 \mathrm{~h}$ for normal time. The analysis of oil pressed from material obtained after the soaking and spraying treatment of $(\mathrm{N} / \mathrm{O}) \mathrm{AgNC}$ plants revealed a higher stability of the oil relative to the control. The induction time was $5.68 \mathrm{~h}$ and the normal time $26.46 \mathrm{~h}$, i.e., respectively, $20.34 \%$ and $4.0 \%$ higher than in the control. After the application of the copper nanocolloid in the $(\mathrm{N} / \mathrm{O})$ CuNC variant, the induction time was $5.70 \mathrm{~h}$ and the normal time $29.32 \mathrm{~h}$, i.e., respectively, $21.19 \%$ and $17.07 \%$ higher. The rapeseed oil in the $(\mathrm{O}) \mathrm{AgNC}$ variant (one-fold application of nanocolloids) had the induction time of $4.82 \mathrm{~h}$, which indicated a $2.12 \%$ increase of stability, but reduction of normal time to $25.46 \mathrm{~h}$. In the (O) CuNC variant, the oil induction time increased by $6.99 \%$ relative to the control and the normal time statistically significantly increased by $7.22 \%$.

Table 3. Acid number, peroxide number and oil induction time.

\begin{tabular}{|c|c|c|c|c|c|}
\hline \multirow{2}{*}{ Year } & \multirow{2}{*}{ Sample } & \multicolumn{4}{|c|}{ Virgin Oil } \\
\hline & & \multicolumn{2}{|c|}{ Oxidative Stability [h] } & $\mathrm{AN}$ [mg KOH·g $\left.{ }^{-1}\right]$ & $\mathrm{PN}\left[\mathrm{mmol} \mathrm{O}_{2} \cdot \mathrm{kg}^{-1}\right]$ \\
\hline \multirow{5}{*}{2016} & Control & $\begin{array}{l}\text { induction time } \\
\text { normal time }\end{array}$ & $\begin{array}{l}4.72 \pm 0.01 \mathrm{~A} \\
25.48 \pm 0.3 \mathrm{D}\end{array}$ & $1.90 \pm 0.01 \mathrm{~A}$ & $3.16 \pm 0.01 \mathrm{~A}$ \\
\hline & (O) AgNC & $\begin{array}{l}\text { induction time } \\
\text { normal time }\end{array}$ & $\begin{array}{c}4.82 \pm 0.05 \mathrm{~A} \\
25.46 \pm 0.03 \mathrm{D}\end{array}$ & $2.56 \pm 0.01 \mathrm{~A}$ & $4.72 \pm 0.01 \mathrm{aB}$ \\
\hline & (O) CuNC & $\begin{array}{l}\text { induction time } \\
\text { normal time }\end{array}$ & $\begin{array}{c}5.05 \pm 0.08 \mathrm{~A} \\
27.32 \pm 0.92 \mathrm{aB}\end{array}$ & $2.46 \pm 0.01 \mathrm{~A}$ & $4.36 \pm 0.02 \mathrm{aB}$ \\
\hline & $(\mathrm{N} / \mathrm{O}) \mathrm{AgNC}$ & $\begin{array}{l}\text { induction time } \\
\text { normal time }\end{array}$ & $\begin{array}{l}5.68 \pm 0.22 \mathrm{aA} \\
26.46 \pm 1.1 \mathrm{aB}\end{array}$ & $2.89 \pm 0.01 \mathrm{aA}$ & $4.39 \pm 0.01 \mathrm{aB}$ \\
\hline & $(\mathrm{N} / \mathrm{O}) \mathrm{CuNC}$ & $\begin{array}{l}\text { induction time } \\
\text { normal time }\end{array}$ & $\begin{array}{r}5.70 \pm 0.24 \mathrm{aA} \\
29.32 \pm 1.36 \mathrm{aA}\end{array}$ & $1.92 \pm 0.01 \mathrm{~A}$ & $3.28 \pm 0.02 \mathrm{~A}$ \\
\hline \multirow{5}{*}{2017} & Control & $\begin{array}{l}\text { induction time } \\
\text { normal time }\end{array}$ & $\begin{array}{l}5.52 \pm 0.02 \mathrm{~A} \\
27.2 \pm 0.03 \mathrm{~B}\end{array}$ & $1.61 \pm 0.01 \mathrm{~A}$ & $2.10 \pm 0.01 \mathrm{C}$ \\
\hline & (O) AgNC & $\begin{array}{l}\text { induction time } \\
\text { normal time }\end{array}$ & $\begin{array}{c}5.25 \pm 0.02 \mathrm{~A} \\
28.8 \pm 0.22 \mathrm{aC}\end{array}$ & $1.66 \pm 0.01 \mathrm{~A}$ & $3.83 \pm 0.01 \mathrm{aA}$ \\
\hline & (O) $\mathrm{CuNC}$ & $\begin{array}{l}\text { induction time } \\
\text { normal time }\end{array}$ & $\begin{array}{l}5.52 \pm 0.03 \mathrm{~A} \\
27.4 \pm 0.31 \mathrm{~B}\end{array}$ & $2.06 \pm 0.01 \mathrm{~A}$ & $3.58 \pm 0.01 \mathrm{aA}$ \\
\hline & $(\mathrm{N} / \mathrm{O}) \mathrm{AgNC}$ & $\begin{array}{l}\text { induction time } \\
\text { normal time }\end{array}$ & $\begin{array}{r}5.60 \pm 0.03 \mathrm{~A} \\
29.9 \pm 0.03 \mathrm{aA}\end{array}$ & $2.65 \pm 0.02 \mathrm{aA}$ & $4.53 \pm 0.20 \mathrm{aB}$ \\
\hline & $(\mathrm{N} / \mathrm{O}) \mathrm{CuNC}$ & $\begin{array}{l}\text { induction time } \\
\text { normal time }\end{array}$ & $\begin{array}{r}5.66 \pm 0.02 \mathrm{~A} \\
29.8 \pm 0.01 \mathrm{aA}\end{array}$ & $2.45 \pm 0.02 \mathrm{~A}$ & $3.20 \pm 0.01 \mathrm{aA}$ \\
\hline
\end{tabular}

a, statistically significant cultivar differences relative to the control; A-D, statistically significant differences between samples under the same field experiment; mean values marked with the same letter are not statistically significantly different $(p>0.05)$.

Application of nanoparticles was strongly positively $\left(R^{2}=0.91\right)$ correlated, at the significance level of $p<0.05$, with the induction time and the normal time in the analyzed oil samples.

The AN value for the control oil was $1.90 \mathrm{mg} \mathrm{KOH} \cdot \mathrm{g}^{-1}$, and after the application of nanocolloids, the respective values were within the range of 1.92 to $2.89 \mathrm{mg} \mathrm{KOH} \cdot \mathrm{g}^{-1}$ (Table 3.). There were slight discrepancies in AN values for samples treated with $\mathrm{AgNC}$ and $\mathrm{CuNC}$ relative to the control. The obtained values were higher than in the control sample by between $1.58 \%(\mathrm{~N} / \mathrm{O}) \mathrm{CuNC}$ and $52.11 \%$ $(\mathrm{N} / \mathrm{O}) \mathrm{AgNC}$, the latter showing threshold statistical significance.

The peroxide number $(\mathrm{PN})$ values in rapeseed oil obtained from samples treated with nanocolloids were similar and higher than the value obtained for the control sample, i.e., $3.16 \mathrm{mmolO} \cdot \mathrm{kg}^{-1}$. After spraying with nanocolloids, the same was statistically significantly increased by $49.4 \%$ for (O) AgNC, $37.9 \%$ for $(\mathrm{O}) \mathrm{CuNC}$, and $38.92 \%$ for $(\mathrm{N} / \mathrm{O}) \mathrm{AgNC}$. It appears that increase in PN number is a stress response. 
The AN values recorded for virgin oil pressed from the 2017 control sample showed higher oxidative stability when compared to the previous year. The obtained value of $5.52 \mathrm{~h}$ was $17 \%$ higher than that from 2016. In the case of nanocolloid application, the oil's oxidative stability was increased, but not to a statistically significant degree, after the treatment of both seeds and plants with the use of either nanopreparation. For (N/O) AgNC and (N/O) CuNC the value was respectively $1.5 \%$ and $2.5 \%$ higher compared to the control. The obtained normal time values were higher compared to the control $(28.8 \mathrm{~h})$ in most experimental variants. They were within the range from $27.40 \mathrm{~h}$ to $29.9 \mathrm{~h}$, which constituted an increase by between $0.74 \%$ for $(\mathrm{O}) \mathrm{CuNC}$ and $9.93 \%$ for $(\mathrm{N} / \mathrm{O}) \mathrm{AgNC}$.

AN for the control sample oil was $1.95 \mathrm{mg} \mathrm{KOH} \cdot \mathrm{g}^{-1}$, and after the nanocolloid treatment, the value was within the range from 1.92 to $2.79 \mathrm{mg} \mathrm{KOH} \cdot \mathrm{h}^{-1}$ (Table 3). After the application of nanosolutions, the acid number of the analyzed oil increased. However, the only statistically significant change was observed after double application of silver nanocolloid (N/O) AgNC where the value increased by $100 \%$ relative to the control.

The concentration of nanoparticles was strongly positively $\left(R^{2}=0.77\right)$ correlated, at the significance level of $p<0.05$, with the acid number (AN) in the analyzed oil samples.

The peroxide number of the control sample was $2.10 \mathrm{mmol} \mathrm{O} 2 \cdot \mathrm{kg}^{-1}$. After nanocolloid treatment, a statistically significant increase thereof was observed in all experimental variants, ranging from $52.4 \%$ for $(\mathrm{N} / \mathrm{O})$ CuNC to $115 \%$ for $(\mathrm{N} / \mathrm{O})$ AgNC.

The metals with prooxidative characteristics in the process of oil autooxidation include, e.g., iron, copper, and manganese. In 2016, the content of silver in the studied oil samples increased, regardless of the nanocolloid treatment, although the increase was not statistically significant (Table 4). In most cases, the copper content in the oil decreased. Statistically significant changes were observed after soaking seeds and spraying plants with $(\mathrm{N} / \mathrm{O}) \mathrm{CuNC}$ where the copper content decreased by as much as $98 \%\left(0.01 \mu \mathrm{g} \cdot \mathrm{g}^{-1}\right)$ compared to the control $\left(0.55 \mu \mathrm{g} \cdot \mathrm{g}^{-1}\right)$. Application of silver nanocolloid resulted in Fe content decreasing by $0.02 \%$ in the one-fold sprayed sample, and in the case of double application (soaking and spraying) it increased by $9.5 \%$ relative to the control. The content of manganese (Mn) slightly increased in both experimental variants, respectively, by $3 \%$ and $17 \%$ relative to the control. After the application of the nanocopper solution, in both experimental variants $(\mathrm{O}) \mathrm{CuNC}$ and $(\mathrm{N} / \mathrm{O})$ CuNC, the values increased compared to the control, respectively, by $6.0 \%$ and $6.26 \%$.

Table 4. Content of metal ions in rapeseed oil.

\begin{tabular}{ccccccc}
\hline \multirow{2}{*}{ Year } & Metal & Control & (O) AgNC & (O) CuNC & (N/O) AgNC & (N/O) CuNC \\
\cline { 4 - 7 } & & & \multicolumn{4}{c}{$\mu g \cdot \mathbf{g}^{-1}$} \\
\hline \multirow{3}{*}{2016} & $\mathrm{Ag}$ & $1.96 \pm 0.83$ & $2.46 \pm 0.34$ & $2.94 \pm 0.64 \mathrm{a}$ & $2.37 \pm 0.40$ & $2.44 \pm 0.72$ \\
& $\mathrm{Cu}$ & $0.55 \pm 0.04$ & $0.56 \pm 0.03$ & $0.51 \pm 0.06$ & $0.49 \pm 0,02$ & $0.01 \pm 0.01 \mathrm{a}$ \\
& $\mathrm{Fe}$ & $48.1 \pm 0.27$ & $48.09 \pm 0.16$ & $51.03 \pm 0.11 \mathrm{a}$ & $52.64 \pm 0.43 \mathrm{a}$ & $51.11 \pm 0.41 \mathrm{a}$ \\
& $\mathrm{Mn}$ & $0.69 \pm 0.01$ & $0.71 \pm 0.01$ & $0.77 \pm 0.01$ & $0.81 \pm 0.02$ & $0.84 \pm 0.01$ \\
\hline \multirow{2}{*}{2017} & $\mathrm{Ag}$ & $1.14 \pm 0.89$ & $3.10 \pm 0.48 \mathrm{a}$ & $2.12 \pm 0.08 \mathrm{a}$ & $2.86 \pm 1.08 \mathrm{a}$ & $1.99 \pm 0.38$ \\
& $\mathrm{Cu}$ & $0.58 \pm 0.01$ & $0.62 \pm 0.04$ & $0.62 \pm 0.05$ & $0.55 \pm 0.03$ & $0.59 \pm 0.03$ \\
& $\mathrm{Fe}$ & $44.7 \pm 0.36$ & $46.87 \pm 0.21$ & $48.23 \pm 0.31 \mathrm{a}$ & $47.7 \pm 0.16 \mathrm{a}$ & $49.82 \pm 0.22 \mathrm{a}$ \\
& $\mathrm{Mn}$ & $0.68 \pm 0.01$ & $0.81 \pm 0.01$ & $1.5 \pm 0.01 \mathrm{a}$ & $0.99 \pm 0.01$ & $1.57 \pm 0.01 \mathrm{a}$ \\
\hline
\end{tabular}

a, statistically significant cultivar differences relative to the control.

In 2017, the content of silver in the analyzed oils increased relative to the control (Table 4). The highest increase was observed after one-fold nanocolloid application-172\% $\left(3.10 \mu \mathrm{g} \cdot \mathrm{g}^{-1}\right)$ compared to the control $\left(1.14 \mu \mathrm{g} \cdot \mathrm{g}^{-1}\right)$. In the case of double application of (N/O) AgNC, the value was 2.86 $\mu \mathrm{g} \cdot \mathrm{g}^{-1}$, i.e., $152 \%$ higher than in the control. Increased silver content in oil was also observed after both single and double application of the copper nanocolloid $(86 \%$ and $74 \%$, respectively, for $(\mathrm{O}) \mathrm{CuNC}$ and (N/O) CuNC). 
Fe content after single and double treatment with silver nanocolloid increased by $4.85 \%$ and $9.44 \%$, respectively, relative to the control. Similar effect was observed for Mn content (statistically significant increase by $19.12 \%$ and $46.0 \%$, respectively).

A slight increase in $\mathrm{Cu}$ content in all variants except double application of the silver nanocolloid $(\mathrm{N} / \mathrm{O}) \mathrm{AgNC}$ was observed where it decreased to $0.55 \mu \mathrm{g} \cdot \mathrm{g}^{-1}$, i.e., by $4.0 \%$ relative to the control. After both single and double application of the nanocopper solution, the Fe content increased by $8.0 \%$ and $11.5 \%$. In the case of Mn, a statistically significant increase of $120.5 \%$ and $130.8 \%$, respectively, relative to the control was observed.

Figure 2 presents the ATR-FTIR spectra for the studied samples of oil produced in 2016 (gray broken line) and 2017 (black solid line). Tables S1 and S2 present all the characteristic bands observed in the oil samples selected for the study. The respective spectra were assigned to vibrations corresponding to particular functional groups.

HCA was performed to observe similarities or dissimilarities between the oil samples. The dissimilarity of different clusters was defined by Euclidean distance and calculated by single linkage method. The results obtained were presented in the dendrogram structure, showing the different groups. Figure 3 presents the plot obtained from the 10 oil samples. Considering the cut-off of 0.7 dissimilarity units, we can distinguish three clusters. The first, biggest cluster, aggregated on the far left arm of the dendrogram. This cluster was formed in five oils from 2017. The second cluster was composed of oil samples from 2016. Two samples, namely control and fertilized with nanocopper, were aggregated in third cluster on the right arm of the dendrogram. Hierarchical cluster analysis shows that the samples from all variations closely depend on the species and the type of fertilization.

The similarity analysis of the IR spectra of the 10 oils samples is provided in Table 5 . As shown in Table 5 (visualization in Figure 4), the FTIR spectra of oils from 2017 with different nanometals showed over 0.98 similarity, which indicated that the oils in these samples were generally similar. This confirmed the results obtained in the HCA. However, the similarity values for oils from 2017 and 2016 samples were very low. Samples F-2017-(O) CuNC and F-2017-(N/O) CuNC had the lowest absolute similarity value (0.07). These results indicate that significant differences in samples compositions existed between the respective years.

To more precisely discriminate the relationship between the investigated objects, the $1850-700 \mathrm{~cm}^{-1}$ band was selected as the fingerprint characteristic spectra and PCA was chosen at the main method of analysis [31]. As shown in Figure 5, a three-dimensional scatter plot with the principal components PC1, PC2 and PC 3 was obtained from the FTIR spectra of different oil samples after PCA. To receive more information about the essential differences of oil compounds using the PCA model, loading factors were abstracted, and the loading factors atlas was drawn at a range of wave numbers between $1850 \mathrm{~cm}^{-1}$ and $700 \mathrm{~cm}^{-1}$ (Figure 6). PC1, PC2 and PC3 are main factors in the PCA model with a high contribution rate of $\mathrm{PC} 1$ which amounts to $87 \%$. It means that PC1, PC2 and PC 3 are sufficient for the illustration of the discrepancies in the composition of different oil samples. Peaks with the lowest contribution rate to $\mathrm{PC} 1$ included peak with maximum at c.a. $-1400 \mathrm{~cm}^{-1}$ and $1670 \mathrm{~cm}^{-1}$ (Figure $6 \mathrm{~A}$ ). These peaks were closely related to the characteristic absorptions originated from methyl groups in aliphatic chains of the examined oils [32]. Peaks with the lowest contribution rate to PC2 included $-1160 \mathrm{~cm}^{-1}$ (Figure 6B). This peak was strongly associated with vibrations of the methylene group. In this case, deformational vibrations in this group appear at the wavenumbers of $1160 \mathrm{~cm}^{-1}$ and $1158-1163 \mathrm{~cm}^{-1}$. Peaks with a larger contribution rate to PC3 include peaks corresponding to the lowest contribution to the rate of PC1 (Figure 6C). These results indicate that the differences between considered oils are mainly reflected in the different shape of the bands located between $1780 \mathrm{~cm}^{-1}$ and $1670 \mathrm{~cm}^{-1}$. This result agrees with that of the FTIR analysis. The use of FTIR combined with PCA can more objectively assess the quality of the investigated samples. 


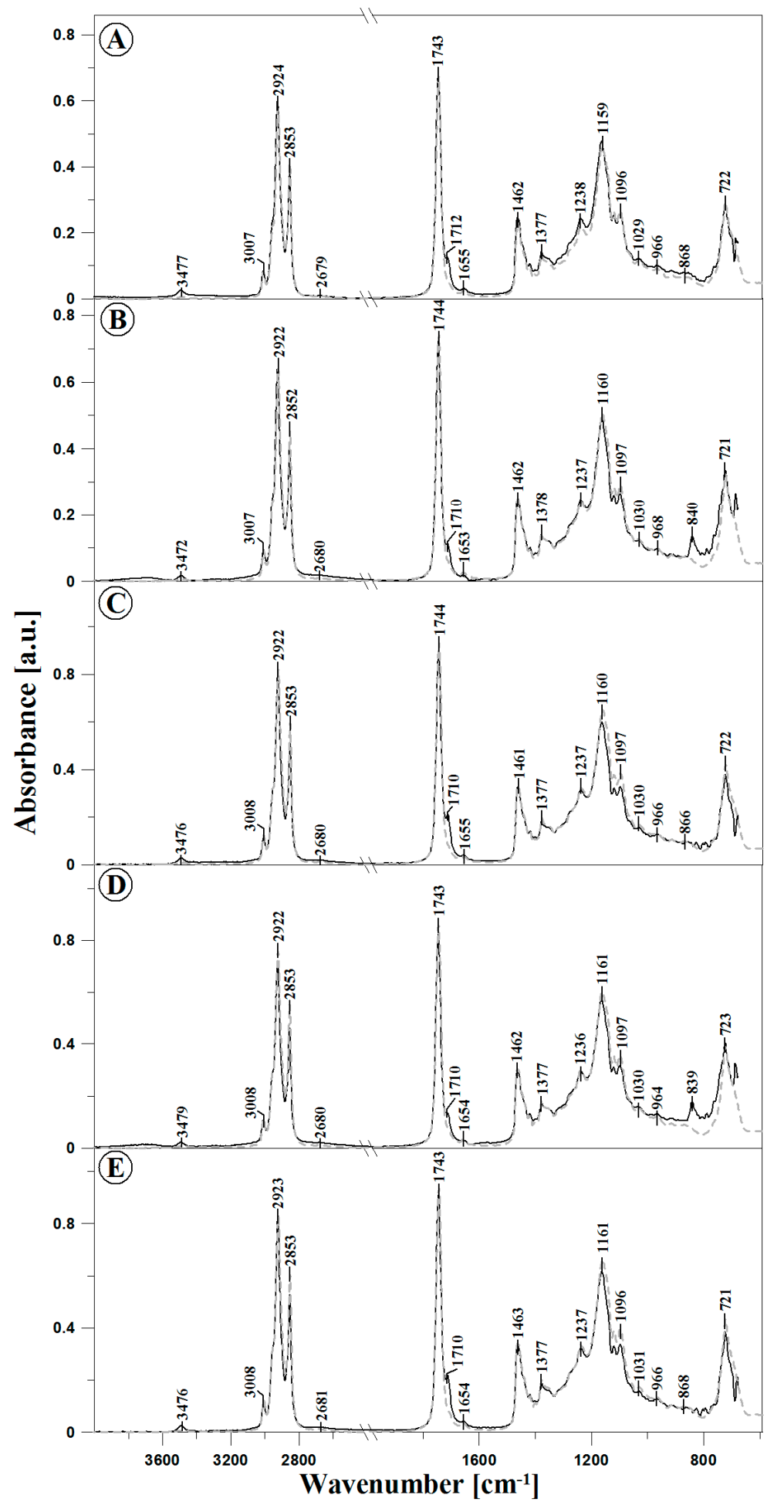

Figure 2. Exemplary ATR-FTIR spectra of the studied rapeseed oil samples from 2016 (gray broken line) and 2017 (black solid line): (A) control; (B) (O) AgNC; (C) (O) CuNC; (D) (N/O) AgNC; and (E) $(\mathrm{N} / \mathrm{O}) \mathrm{CuNC}$. The spectra are presented in the spectral range of $590-4000 \mathrm{~cm}^{-1}$. Spectra are normalized at the intensity of a peak at $1743 \mathrm{~cm}^{-1}$. 
The first principal component was the most important ingredient, and its variance contribution ratio was $87 \%$; the second principal component showed a variance contribution rate of $12.1 \%$, and the third principal component of $0.8 \%$. The first three main components provided $99.9 \%$ contribution ratio in total, with only $0.01 \%$ of the information being lost. This indicates that the first three principal components expressed $99.9 \%$ of all information.

Samples F-2016-C and F-2016-(O)AgNC (Group II) were closely related in the three-dimensional graph (Figure 5.) and were clearly classified as a separate group. Although the remaining samples from 2016 belonged to a different group, these three were still classified as a region close to Group III, presumably due to the method of fertilization. In addition, the IR spectral characteristics of samples from Group I revealed significant differences from the other five samples and had the greatest distance with the same in the scatter plot (Figure 5).

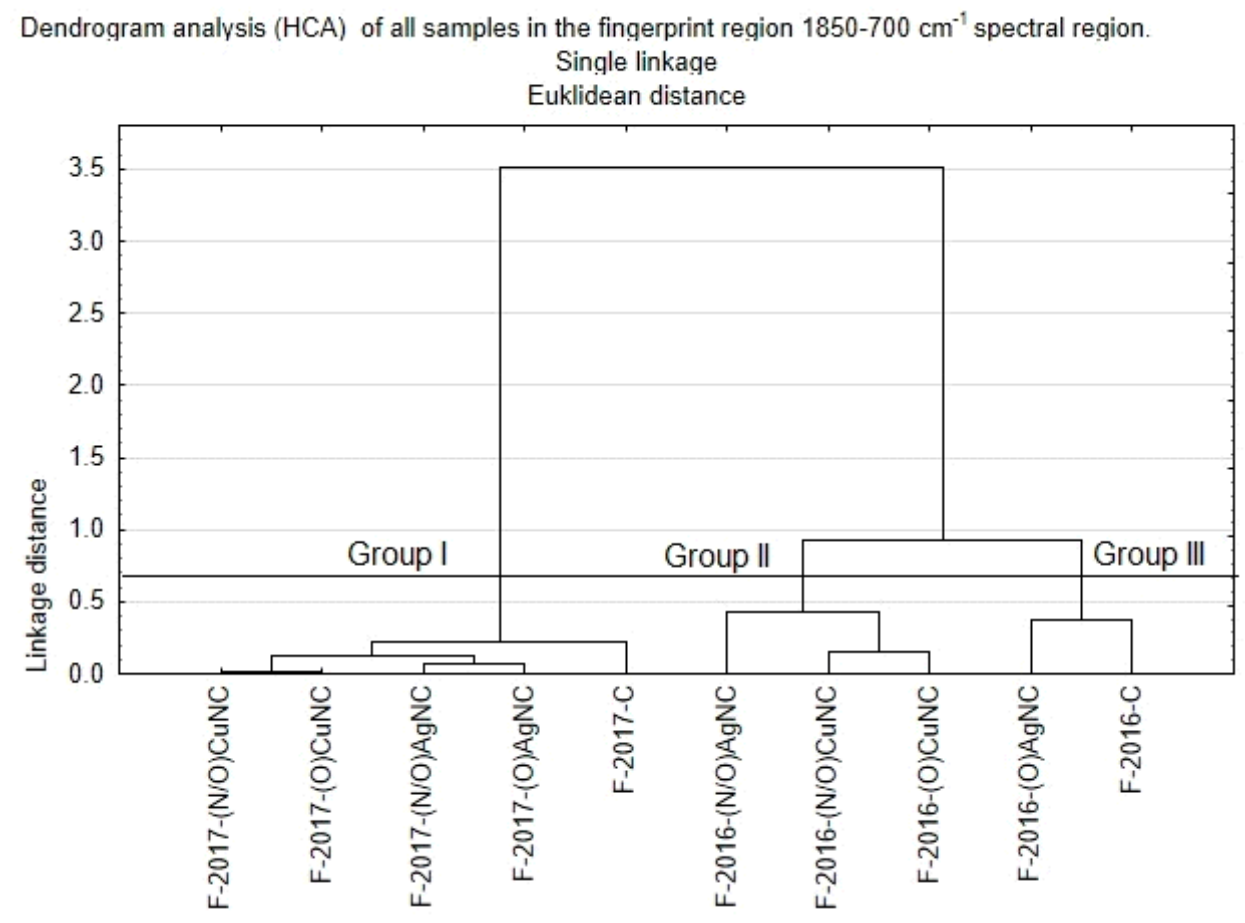

Figure 3. Hierarchical cluster dendrogram constructed from FTIR data for 10 oil samples.

Table 5. The similarity of FTIR spectra of 10 oil samples.

\begin{tabular}{|c|c|c|c|c|c|c|c|c|c|c|c|}
\hline \multirow[t]{2}{*}{ Year } & \multirow[t]{2}{*}{ Sample } & Control & $\begin{array}{c}(\mathrm{O}) \\
\text { AgNC }\end{array}$ & $\begin{array}{c}(\mathrm{O}) \\
\text { CuNC }\end{array}$ & $\begin{array}{l}(\mathrm{N} / \mathrm{O}) \\
\mathrm{CuNC}\end{array}$ & $\begin{array}{l}\text { (N/O) } \\
\text { AgNC }\end{array}$ & Control & $\begin{array}{c}(\mathrm{O}) \\
\text { AgNC }\end{array}$ & $\begin{array}{c}(\mathrm{O}) \\
\text { CuNC }\end{array}$ & $\begin{array}{l}\text { (N/O) } \\
\text { AgNC }\end{array}$ & $\begin{array}{l}\text { (N/O) } \\
\text { CuNC }\end{array}$ \\
\hline & & \multicolumn{5}{|c|}{2016} & \multicolumn{5}{|c|}{2017} \\
\hline \multirow{5}{*}{2016} & Control & 1.00 & 0.99 & 0.99 & 0.99 & 0.99 & -0.08 & -0.09 & -0.07 & -0.09 & -0.07 \\
\hline & (O) AgNC & & 1.00 & 0.99 & 0.99 & 0.99 & -0.08 & -0.09 & -0.07 & -0.09 & -0.07 \\
\hline & (O) CuNC & & & 1.00 & 0.99 & 0.99 & -0.08 & -0.08 & -0.07 & -0.09 & -0.07 \\
\hline & $(\mathrm{N} / \mathrm{O}) \mathrm{CuNC}$ & & & & 1.00 & 0.99 & -0.07 & -0.08 & -0.07 & -0.09 & -0.07 \\
\hline & $(\mathrm{N} / \mathrm{O}) \mathrm{AgNC}$ & & & & & 1.00 & -0.08 & -0.08 & -0.07 & -0.09 & -0.07 \\
\hline \multirow{5}{*}{2017} & Control & & & & & & 1.00 & 0.99 & 0.99 & 0.98 & 0.99 \\
\hline & (O) AgNC & & & & & & & 1.00 & 0.99 & 0.99 & 0.98 \\
\hline & (O) CuNC & & & & & & & & 1.00 & 0.99 & 0.99 \\
\hline & $(\mathrm{N} / \mathrm{O}) \mathrm{AgNC}$ & & & & & & & & & 1.00 & 0.98 \\
\hline & $(\mathrm{N} / \mathrm{O}) \mathrm{CuNC}$ & & & & & & & & & & 1.00 \\
\hline
\end{tabular}


This result correlates with that of the hierarchical cluster analysis and the similar analysis of FTIR fingerprint of oils. As we know, the scatter plot does not classify objects at every distance level as accurately as the clustering graph, but it can clearly reflect the relationships between the investigated objects. Therefore, the use of complementary analytical methods provides researchers with important information about the quality of oils.

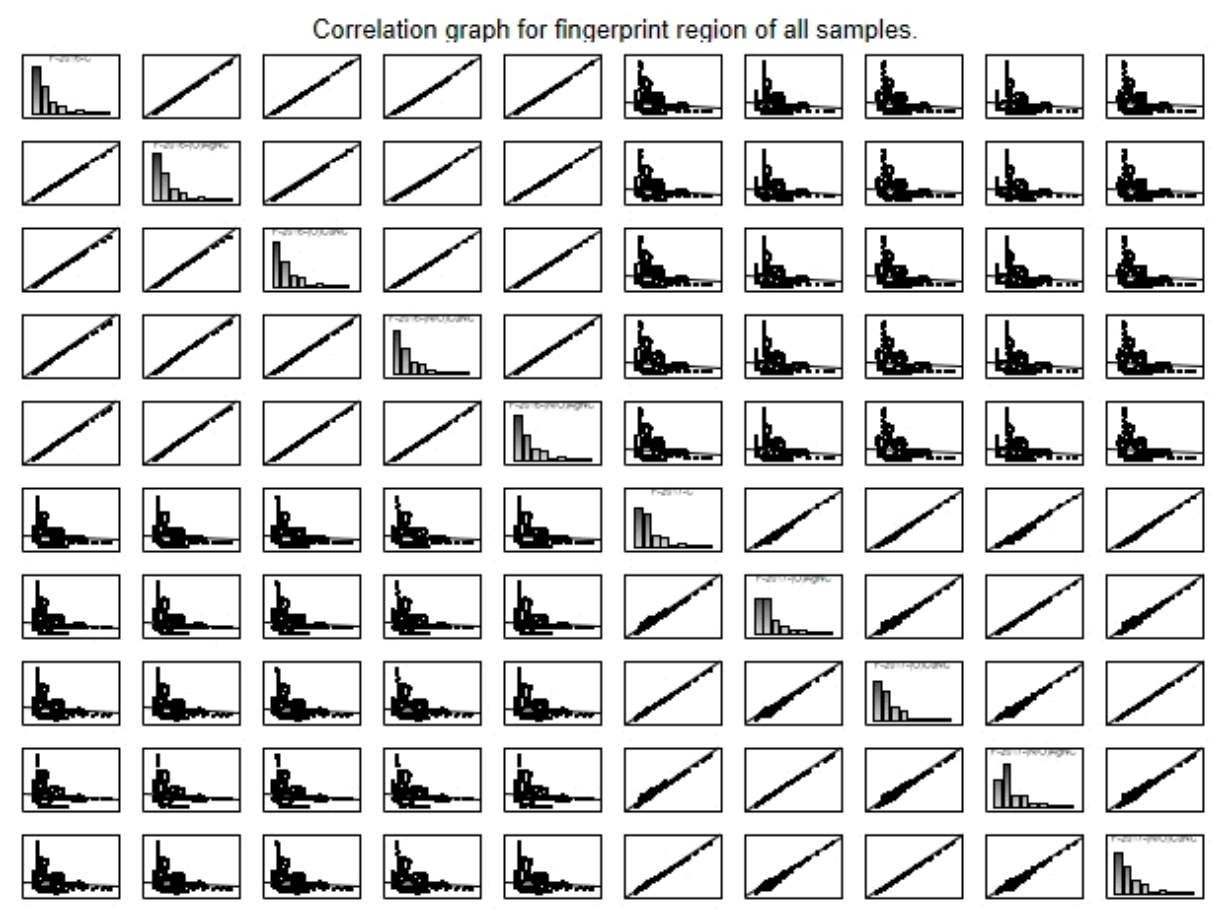

Figure 4. Plot of the pairwise correlations between the oil samples from the FT-IR spectra. Diagonal values are measures of sampling adequacy for individual fingerprint regions of oil samples; off-diagonal are anti-image correlations. In the case of high values of correlation, we have (nearly) linear dependence, otherwise nonlinear.
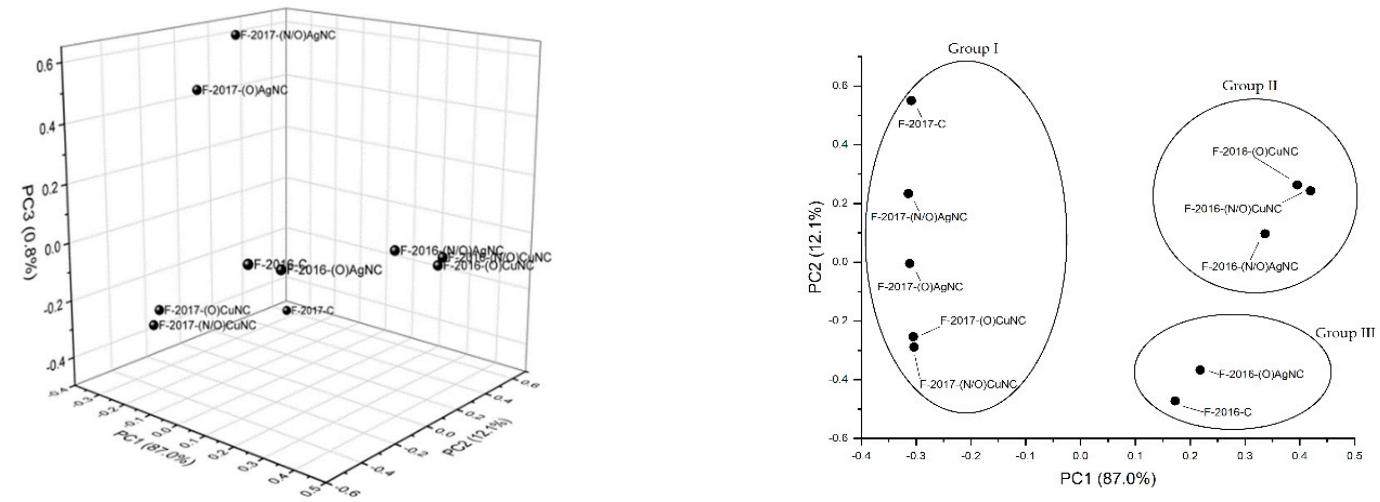

Figure 5. (left) Scattered scores plot $(\mathrm{PC} 1 \times \mathrm{PC} 2 \times \mathrm{PC} 3)$ based on the FTIR spectral fingerprint of oil samples; and (right) scattered scores plot $(\mathrm{PC} 1 \times \mathrm{PC} 2)$ based on the FTIR spectral fingerprint of oil samples. 


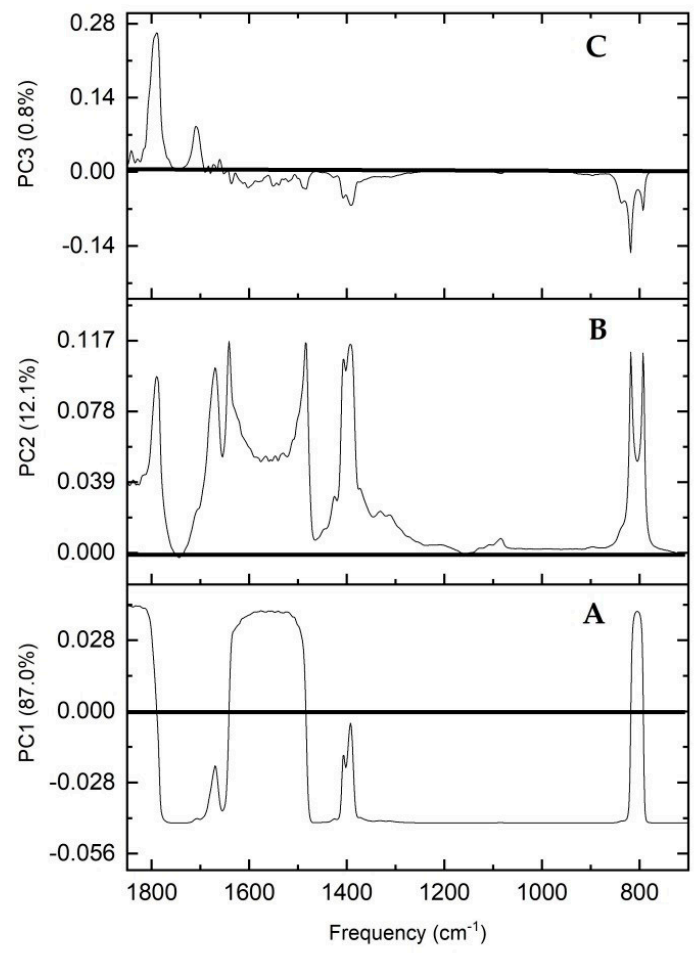

Figure 6. The loading factors of PCA: (A) PCA1; (B) PCA2; (C) PCA3.

\section{Discussion}

The effect of nanoparticles on plants is a relatively new area of research. The effects of nanoparticle interactions with plants can range from small changes in the soil environment to changes in the morphology of physiology and plant genetics. Although the mechanism of interaction of nanoparticles with plants is not fully understood, it is assumed that, depending on their properties, they can form complexes with transport proteins or root exudates, as a result of which they can be transferred to the plant system [33]. Apart from uptake of nanoparticles through roots, foliar uptake is also possible as they are able to penetrate leaf surfaces through stomata [34].

The effect impact of nanomaterials on plants is quite complex. Even the same type of nanoparticles can interact differently with biological systems (registered effects can be positive, negative or neutral) and species-dependent. The effect can be also dose-dependent which means that the same nanomaterials which can be toxic at high concentrations can bring up positive effects at low when their concentration is low [35]. Of importance are also the species of plants treated with nanoparticles. Beneficial effects of some kinds of nanoparticles on certain plant species are manifested in increasing the seed germination, increasing yield or in plant disease control [36,37].

On the other hand, crops subjected to nanoparticles can exhibit adaptive processes in response to stress, which include endocytosis of nanoparticles, modification of genes involved in cell division, and reduced photosynthesis, fruit yields, nutrition quality and nitrogen binding, among others [38].

There is no information in the literature on the impact of nanoparticles on the quality of plant products such as oil obtained from seeds. For this reason, it is difficult to provide mechanisms responsible for changes in the physico-chemical properties of oils.

Carotenoid and chlorophyll pigments are present in all plant oils and their content depends on the cultivar and maturity of the raw material, as well as the production and refinement methods applied [39]. As observed by Ciecierska and Obiedziński [40], virgin oils obtained without the use of chemical refinement methods may be valuable food products provided that they do not contain harmful chemical or microbiological impurities, including mycotoxins, metals accelerating the oxidation processes (iron, copper), or chlorophyll pigments which are usually removed in the course of chemical refinement. Excessive content of chlorophyll negatively affect the quality (smell) and oxidative stability of oil [41,42] 
due to its prooxidative properties, it also darkens the color of the product [43]. Apart from chlorophyll pigments, rapeseeds also contain considerable amounts of carotenoids. The presence of carotenoids in oil is important due to their antioxidant provitamin properties [44].

The content of pigments ( $\mathrm{chl} a, \mathrm{chl} b$, and carotenoids) in the virgin oil obtained from rape seeds harvested during the field experiment in both 2016 and 2017 was, in most cases, statistically significantly higher relative to the control. The content of these pigments compared to oil pressed from traditionally cultivated seeds (using standard plant protection agents) tends to be higher. In cold pressed oils, e.g., from winter rapeseeds harvested from a traditional cultivation, the content of chlorophyll $a$ and $b$ as well as carotenoids was significantly lower, specifically $1.23 \mu \mathrm{g} \cdot \mathrm{mL}^{-1}(\mathrm{chl} a), 2.02 \mu \mathrm{g} \cdot \mathrm{mL}^{-1}(\mathrm{chl} b)$, and $8.41 \mu \mathrm{g} \cdot \mathrm{mL}^{-1}$ (carotenoids) [45].

Ghorbanpour and Hatami [35] showed that the application of silver nanoparticles on $P$ graveolus caused changes in the content of photosynthetic pigments depending on the dose of nanoparticles. Small doses had a stimulating effect on the synthesis of pigments and large ones caused its inhibition. An increase in chlorophyll content under the influence of nanoparticles has also been observed [46] for Brassica juncea.

As previously published [35], such an effect can be produced when plants activate their defense mechanisms by changing antioxidant compounds to combat the stress.

The changes in the content of pigments can be additionally confirmed by the analysis of color of the samples. It indicates that oils from plants treated with nanocolloid are darker in color (lower $\mathrm{L}^{*}$ ) but have similar shade of yellow (no difference in $\mathrm{h}$ although positive $\mathrm{h}$ values indicate the addition of green in the general yellow color). A decrease in the amount of admixture responsible for the red color is also observed as indicated by the decrease in $\mathrm{a}^{*}$ and $\mathrm{b}^{*}$ parameters (indicating lowering of carotenoid pigments). Chroma $C^{*}$ indicates the color saturation, i.e., the proportions at which the dominant color is mixed with white, black or gray, and is therefore a measure of the purity and intensity of color in subjective terms. The more saturated the color is, the more it is perceived as more vivid and bright. The measurements show that all the oils treated with nanocolloids became less vivid, which can be caused by the increase in chlorophyll content.

For the difference between two colors in the three-dimensional $\mathrm{L}^{*} \mathrm{a}^{*} \mathrm{~b}^{*}$ space, $\Delta \mathrm{H}$ is the Euclidean distance between two points, in this case measured against the background. $\Delta H=1$ is the smallest color difference the human eye can see. As seen from the data, it is difficult to see the difference with a bare eye.

Samples from the second year showed a higher level of darkness compared to the previous year. It is very difficult to explain this phenomenon both for 2016 and 2017 as it cannot be directly connected to the presence of photosynthetic pigments since the examined oils contain similar amounts of chlorophylls (green color) and carotenoids (yellow and red color) (see Table 1).

Generally lower $a^{*}$ and $b^{*}$ values were observed in the second experimental year, which indicates lower yellowness of the samples and a smaller contribution of the red/magenta shade in a general yellow color.

Although no statistical differences were found, one can observe a decrease of the hue angle value. This indicates that the basic yellow color is clearer than that observed in 2016.

Oxidative stability is a measure of oil quality, particularly with regard to virgin oils containing natural antioxidants (e.g., carotenoids), as well as undesirable prooxidative substances (e.g., chlorophylls and metals) that are normally eliminated in the refinement process [47]. Rancimat tests indicated that cold pressed rapeseed oil was characterized by induction times within the range of 4.05-4.5 $\mathrm{h}[48,49]$. The conducted experiment revealed that oils pressed from spring rapeseeds in the variants using nanocolloids were characterized by higher oxidative stability compared to the control ( $4.72 \mathrm{~h}$ ). Seed treatment using nanocolloids followed by spraying the plants with the same during the growth stage contributed, in most cases, to increased oxidative stability of the analyzed virgin oil in both years of the experiment, up to $5.70 \mathrm{~h}(\mathrm{~N} / \mathrm{O}) \mathrm{CuNC}$ in 2016 and $5.66 \mathrm{~h}(\mathrm{~N} / \mathrm{O}) \mathrm{CuNC}$ in 2017. 
The process of oxidation is affected by a number of factors, including atmospheric oxygen, heat, heavy metals, or light exposure, all of which facilitate initiation of the oxidation process. The presence of trace metals in oils may be of natural origin or due to the processes employed in the course of cultivation and seed processing. Their presence is dependent on, e.g., seed processing itself (including stages such as bleaching, hardening, refinement, or deodorization), corrosion of the processing equipment, packaging procedures, and residual traces of fungicides used during cultivation [50].

The presence of heavy metals in oils may negatively affect their smell and taste. Catalytic oxidation of oil with molecular oxygen by metal ions (particularly copper) leads to so-called oil rancidity [51]. Metals such as iron, copper, chromium, zinc, and cobalt present in rapeseed oil undergo further reactions under the influence of visible light [52].

In our study, in both the first year and second year of cultivation, we observed elevated silver content in the analyzed oil under both experimental variants $[(\mathrm{O}) \mathrm{AgNC}$ and $(\mathrm{N} / \mathrm{O}) \mathrm{AgNC}]$. Moreover, the oils showed an increase in iron and manganese content, proportional to the amount of the nanosilver solution used.

Other factors, apart from high chlorophyll content, negatively affecting oil durability may include the presence of free fatty acids, as measured by the acid number (AN), and peroxides, measured by the peroxide number (PN) and treated as the indication of the oil's oxidation (rancidity). These values indicate the initiation of triglyceride hydrolysis and oxidation both in the seeds and the oil. In the oils pressed for the experiment, said values were elevated as compared to the control but did not exceed allowable levels [53]. The highest $\mathrm{AN}$ value was recorded for the oil obtained from plants subjected to twofold treatment with silver nanocolloid (N/O) AgNC $2.89 \mathrm{mgKOH} \cdot \mathrm{g}^{-1}$ in 2016 and $2.65 \mathrm{mgKOH} \cdot \mathrm{g}^{-1}$ in 2017. In the case of PN, the highest values were observed in oils obtained from plants subjected to one silver nanocolloid treatment (O) AgNC $4.72 \mathrm{mmolO} \cdot \mathrm{kg}^{-1}$ in 2016 and two copper nanocolloid treatments (N/O) AgNC $4.53 \mathrm{mmolO} \cdot \mathrm{kg}^{-1}$ in 2017. The registered values were higher from those reported in other studies on cold-pressed oils [54-56].

It should be noted that all infrared spectra (ATR-FTIR) registered for the oils, in both the first and second year of the experiment, revealed very intensive and clear spectra attributable to specific vibrations of particular functional groups present both in typical food ingredients as well in potential materials characteristic of biodiesel fuel. The vast majority of both edible oils and potential fuel oil materials consist primarily of various triglyceride fractions, while the main differences between them are mostly due to the degree and from non-saturation of acyl groups present therein as well as, most importantly, the length of their chains [57]. There have been many reports pertaining to the association of the spectral bands of both plant and animal oils $[32,58,59]$ with specific vibrations of molecules or groupings thereof. However, many bands remain difficult to conclusively associate with specific functional groups.

The analyzed oil samples from both years of the experiment revealed relatively similar infrared spectra. It should be noted, however, that depending on the selected method of fertilization using different nanocolloids, certain differences do appear. Firstly, there were observable differences in terms of band intensity (not shown due to the fact that the spectra were normalized in the peak associated with vibrations of the carbonyl $\mathrm{C}=\mathrm{O}$ group). Secondly, the registered spectra showed slight differences in terms of band location.

One should also mention the vibrations in the region from 900 to $650 \mathrm{~cm}^{-1}$, which correspond to the characteristic deformation vibrations of the $-\mathrm{HC}=\mathrm{CH}$ - groups (cis-conformation, out-of-plane) and wagging vibrations of the same $\left(\delta\left(-\left(\mathrm{CH}_{2}\right) \mathrm{n}-\right.\right.$ and $-\mathrm{HC}=\mathrm{CH}-($ cis- $\left.)\right)[32,57]$.

Next, as we pass to vibrations in higher wavenumber ranges differences are visible in $=\mathrm{C}-\mathrm{H}$ stretching vibrations (tarns-transformation) with the maximum at approximately $3060-3066 \mathrm{~cm}^{-1}$ (Tables S1 and S2) originating from the vibrations of triglyceride fractions $[57,60]$ (low intensity in Figure 2). In turn, for the $=\mathrm{C}-\mathrm{H}$ stretching vibrations in the cis-configuration, very characteristic and intensive vibrations were present with the maximum at approximately $3005-3008 \mathrm{~cm}^{-1}$ (Figure 2 and Tables S1 and S2). Vibrations with the maxima at approximately $2952 / 5,2922 / 4$ and $2852 / 3 \mathrm{~cm}^{-1}$ 
originated from the stretching vibrations of $-\mathrm{C}-\mathrm{H}$ in $-\mathrm{CH}_{3}, \mathrm{CH}_{2}$ groups belonging to the aliphatic groups in triglycerides [32,33,56,57,59].

The spectra of the analyzed oil samples (from different experimental periods) after the application of different spraying/fertilization regimens with colloids containing nanostructures (Figure 2) show clear differences in the shape of the spectra in the region of $1780-1670 \mathrm{~cm}^{-1}$.

Apart from the visible differences in terms of bands with the maximum at approximately $1710-1715 \mathrm{~cm}^{-1}$, it is also worth noting the possibly most important emergence of a very clear band with the maximum at approximately $840 \mathrm{~cm}^{-1}$ (Figure 2B,D) which may originate from the metal-oxygen $(\mathrm{Cu}-\mathrm{O})$ stretching vibrations. The band was observed only for samples treated (in various configurations) with the nanocopper colloid. Its intensity was comparable in both variants, which confirms similar content of metal particles capable of reacting with groups containing oxygen present in the analyzed systems. The position of this band may depend on the degree of hydrogen bonding in the $\mathrm{Cu}-\mathrm{O}-\mathrm{H}$ system [61]. The same confirms the presence of copper nanoparticles in the oil. The band with the maximum at approximately $1100 \mathrm{~cm}^{-1}$ combined with the band at approximately $840 \mathrm{~cm}^{-1}$ may also constitute an enhancement of the symmetric stretching vibrations of the $\mathrm{COO}-$ group resulting for the interaction with $\mathrm{Cu}$ particles. In the case of samples treated with the nanocolloid containing Ag nanoparticles, this band was not present; however, in this case, we observed significantly greater changes in the bands at approximately 1160 and $1100 \mathrm{~cm}^{-1}$ which may originate from the vibrations of $\mathrm{C}-\mathrm{O}-\mathrm{Ag}$, enhancement of $\mathrm{C}-\mathrm{O}$ vibrations which also evidences the effects of $\mathrm{Ag}$ nanoparticles on the analyzed oil samples.

\section{Conclusions}

1. The analysis of quality parameters of oils from seed harvested from the field experiment revealed that, regardless of the year of harvest or method of nanocolloid application, the content of chlorophyll $a$ and $b$ as well as carotenoids was statistically significantly higher compared to the control samples.

2. The oxidative stability of oils pressed from seeds harvested in both years of the experiment and after the application of $(\mathrm{O}) \mathrm{CuNC}$ spray, as well as after soaking seeds and spraying plants with either nanocolloid, was higher or equal to that in the control.

3. Application of Ag nanocolloid resulted in the increased content of this metal in the oil samples. Increase was also observed in concentration of iron and manganese.

4. The use of FTIR analysis combined with chemometrics to investigate the oils compounds can effectively classify and identify the oil samples and suggest reasons for their varying chemical compositions. The results obtained in this study can provide a comprehensive evaluation for oils quality and an optimization evaluation method for quality control. Moreover, valuable information was obtained for oil similarity from different cultivation methods and these data are helpful for the rational utilization, storage and cultivation of plants as a source of valuable oils.

5. The analysis of FTIR spectra revealed the presence of a new band in the lower wavenumber region (with the maximum at approximately $840 \mathrm{~cm}^{-1}$ ) for the oil samples obtained from seeds or plants treated with nanocolloids (of either type). The bands originating from the vibrations of the metal-oxygen system evidence a clear influence of the nanocolloids on the properties of the obtained oils.

Supplementary Materials: The following are available online at http://www.mdpi.com/2073-4395/9/10/643/s1, Table S1: Positions of the absorption bands maxima (2016) with the assignment to the respective vibrations for rapeseed oil after nanosilver and nanocopper treatment, spectral range: 590-4000 $\mathrm{cm}^{-1}$, Table S2: Positions of the absorption bands maxima (2017) with the assignment to the respective vibrations for rapeseed oil after nanosilver and nanocopper treatment, spectral range: $590-4000 \mathrm{~cm}^{-1}$. 
Author Contributions: M.K.-plant cultivation, oil extraction, measurements of chlorophylls and carotenoids, basic statistical data analysis, manuscript writing (general aspects); A.M.-FTIR measurements and analysis, manuscript writing (FTIR measurements and discussion); A.S.--measurements of color and metal content, analysis of data, evaluation of biological effect of nanocolloids on the oils, manuscript writing (color and metal content measurements, discussion); G.C.-physico-chemical characterization of nanocolloids, manuscript writing (part concerning nanocolloids characterization and discussion); A.N. (Agnieszka Niemczynowicz) - HCA and PCA analysis, manuscript writing (statistical analysis interpretation); A.N. (Aldona Nowicka)—measurements of size of nanoparticles, writing manuscript concerning nanoparticle sizes.

Funding: The part of research of Agnieszka Niemczynowicz in publication was written as a result of internship in Valencia, Spain, co-financed by the European Union under the European Social Fund (Operational Program Knowledge Education Development), carried out in the project Development Program at the University of Warmia and Mazury in Olsztyn (POWR.03.05. 00-00-Z310/17).

Acknowledgments: The authors Agnieszka Niemczynowicz and Arkadiusz Matwijczuk acknowledge the Cost project CA15126 and CA15216. Authors thank Dariusz Wiacek from Institute of Agrophysics, Polish Academy of Sciences in Lublin, Poland for help with measurements of metal content.

Conflicts of Interest: The authors declare no conflict of interest.

\begin{tabular}{ll}
\multicolumn{2}{l}{ Abbreviations } \\
car & carotenoids $\left(\mu \mathrm{g} \cdot \mathrm{ml}^{-1}\right)$ \\
chl & $a$ chlorophyll $a\left(\mu \mathrm{g} \cdot \mathrm{ml}^{-1}\right)$ \\
chl & $b$ chlorophyll $b\left(\mu \mathrm{g} \cdot \mathrm{mL}^{-1}\right)$ \\
AN & acid number \\
PN & peroxide number \\
ATR-FTIR & attenuated total reflection Fourier-transformed infra red \\
NC & nanocolloids \\
(N/N) & seed soaked in nanocolloid \\
(N/O) & seeds soaked and plants sprayed with nanocolloid \\
AgNC & silver nanocolloid \\
CuNC & copper nanocolloid \\
(N/O)AgNC & seeds soaked and plants sprayed with silver nanocolloid \\
(N/O)CuNC & seeds soaked and plants sprayed with copper nanocolloid \\
SDW & sterile distilled water
\end{tabular}

\section{References}

1. Weiss, J.; Takhistov, P.; McClements, D.J. Functional materials in food nanotechnology. J. Food Sci. 2006, 71, R107-R116. [CrossRef]

2. Srinivas, P.R.; Philbert, M.; Vu, T.Q.; Huang, Q.; Kokini, J.L.; Saos, E.; Chen, H.; Peterson, C.M.; Friedl, K.E.; McDade-Ngutter, C.; et al. Nanotechnology research: Applications in nutritional sciences. J. Nutr. 2010, 140, 119-124. [CrossRef] [PubMed]

3. Fabrega, J.; Luoma, S.N.; Tyler, C.R.; Galloway, T.S.; Lead, J.R. Silver nanoparticles: Behaviour and effects in the aquatic environment. Environ. Int. 2011, 37, 517-531. [CrossRef] [PubMed]

4. Egorova, E.M.; Kubatiev, A.A.; Schvets, V.I. The effect of metal nanoparticles on biological objects (analysis of the literature). In Biological Effects of Metal Nanoparticles; Springer: Cham, Switzerland, 2016. [CrossRef]

5. Agnihotri, S.; Mukherji, S.; Mukherji, S. Size-controlled silver nanoparticles synthesized over the range 5-100 nm using the same protocol and their antibacterial efficacy. RSC Adv. 2014, 4, 3974-3983. [CrossRef]

6. Chen, H. Metal based nanoparticles in agricultural system: Behavior, transport, and interaction with plants. Chem. Speciat. Bioavailab. 2018, 30, 123-134. [CrossRef]

7. Chowdappa, P.; Gowda, S. Nanotechnology in crop protection: Status and scope. Pest Manag. Hortic. Ecosyst. 2013, 19, 131-151.

8. Nair, R.; Varghese, S.H.; Nair, B.G.; Maekawa, T.; Yoshida, Y.; Kumar, D.S. Nanoparticulate material delivery to plants. Plant Sci. 2010, 179, 154-163. [CrossRef]

9. Zheng, L.; Hong, F.; Lu, S.; Liu, C. Effect of nano- $\mathrm{TiO}_{2}$ on strength of naturally aged seeds and growth of spinach. Biol. Trace Elem. Res. 2005, 104, 83-91. [CrossRef] 
10. Gao, F.Q.; Hong, F.S.; Liu, C.; Zheng, L.; Su, M.Y. Mechanism of nano-anatase $\mathrm{TiO}_{2}$ on promoting photosynthetic carbon reaction of spinach: Inducing complex of Rubisco-Rubisco activase. Biol. Trace Elem. Res. 2006, 111, 286-301. [CrossRef]

11. Szajdek, A.; Borowska, J. Antioxidative properties on food of plant origin. Food. Sci. Technol. Qual. 2004, 4, 5-28.

12. Gunstone, F.D. Vegetable Oils. In Bailey's Industrial Oil and Fat Products, Volume 1. Edible Oil and Fat Products: Chemistry, Properties, and Health Effects, 6th ed.; Shahidi, F., Ed.; John Wiley \& Sons: Haboken, NJ, USA, 2005; pp. 213-267.

13. Kamal-Eldin, A. Minor Components of Fats and Oils. In Bailey's Industrial Oil and Fat Products, Volume 3, Edible Oil and Fat Products: Specialty Oils and Oil Products, Part 2, 6th ed.; Shahidi, F., Ed.; John Wiley \& Sons: Haboken, NJ, USA, 2005; pp. 319-359.

14. Robak, J.; Zachwieja, Z. Significance of carotenoids in human diet and treatment of certain diseases. Bromatol. Toxicol. Chem. 1998, XLVII, 295-301.

15. Sikwese, F.E.; Duodu, K.G. Antioxidant effect of a crude phenolic extract from sorghum bran in sunflower oil in the presence of ferric ions. Food Chem. 2007, 104, 324-331. [CrossRef]

16. Frankel, E.N. (Ed.) Lipid Oxidation; The Oily Press: Dundee, UK, 1998.

17. Choe, E.; Min, D.B. Chemistry and reactions of reactive oxygen species in foods. Crit. Rev. Food Sci. 2006, 46, 1-22. [CrossRef] [PubMed]

18. Pingret, D.; Durand, G.; Fabiano-Tixier, A.; Rockenbauer, A.; Ginies, C.; Chemat, F. Degradation of edible oil during food processing by ultrasound, electron paramagnetic resonance, physicochemical, and sensory appreciation. J. Agric. Food Chem. 2012, 60, 7761-7768. [CrossRef] [PubMed]

19. Interesse, F.S.; Ruggiero, P.; Vitagliano, M. Autoxidation of olive oil: Influence of chlorophyll pigments. Ind. Agric. 1971, 9, 318-323.

20. Gutiérrez-Rosales, F.; Garrido-Fernández, J.; Gallardo-Guerrero, L.; Gandul-Rojas, B.; Mínguez-Mosquera, M.I. Action of chlorophylls on the stability of virgin olive oil. J. Am. Oil Chem. Soc. 1992, 69, 866-871. [CrossRef]

21. PN-EN ISO 660:2005. Plant and Animal Fats And oils. Measuring the Acid Number and Acidity. Available online: https://www.iso.org/standard/44879.html (accessed on 11 August 2019).

22. PN-EN ISO 3960:2012. Plant and Animal Fats and Oils. Measuring the Peroxide Number. Iodometric (Visual) Determination of the End Point. Available online: https://www.iso.org/standard/71268.html (accessed on 11 August 2019).

23. PN-EN ISO 6886:2009. Plant and Animal Fats and Oils. Measuring Oxidative Stability (Accelerated Oxidation Test). Available online: https://www.iso.org/standard/69594.html (accessed on 11 August 2019).

24. Lichtenthaler, H.K.; Buschmann, C. Chlorophylls and carotenoids: Measurement and characterization by UV-Vis spectroscopy. In Current Protocols in Food Analytical Chemistry; Wiley \& Sons: New York, NY, USA, 2001; Suppl. 1, pp. F4.3.1-F4.3.8.

25. Brainard, D.H. Color appearance and color difference specification. In Science of Color; Shevell, S., Ed.; Optical Society of America: Washington, DC, USA, 2003.

26. Sujak, A.; Wiącek, D.; Jakubas, D.; Komosa, A.; Kitowski, I. Mallards Anas platyrhynchos shot in Eastern Poland: Ecological risk evaluated by analysis of trace elements in liver. Human Ecol. Risk Assess. 2019, 25, 2116-2132. [CrossRef]

27. Brereton, R.G. Chemometrics: Data Analysis for the Laboratory and Chemical Plant; John Wiley: Chichester, UK, 2003. [CrossRef]

28. Xu, C.J.; Liang, Y.Z.; Chau, F.T.; Heyden, Y.V. Pretreatments of chromatographic fingerprints for quality control of herbal medicines. J. Chromatogr. A 2006, 1134, 253-259. [CrossRef]

29. Li, Y.Q.; Kongvhjgg, D.X.; Wu, H. Analysis and evaluation of essential oil components of cinnamon barks using GC-MS and FTIR spectroscopy. Ind. Crops Prod. 2013, 41, 269-278. [CrossRef]

30. Kim, K.H.; Akase, Z.; Suzuki, T.; Shindo, D. Charging effects on SEM/SIM contrast of metal/insulator system in various metallic coating conditions. Mater. Trans. 2010, 51, 1080-1083. [CrossRef]

31. Abdi, H.; Williams, L.J. Principal component analysis. Wiley Interdiscip. Rev. Comput. Stat. 2010, 2, $433-459$. [CrossRef]

32. Guillén, M.D.; Ruiz, A.; Cabo, N.; Chirinos, R.; Pascual, G. Characterization of sacha inchi (Plukenetia volubilis L.) oil by FTIR spectroscopy and $1 \mathrm{H}$ NMR. comparison with linseed oil. J. Am. Oil Chem. Soc. 2003, 80, 755-762. [CrossRef] 
33. Yadav, T.; Mungray, A.A.; Mungray, A.K. Fabricated nanoparticles: Current status and potential phytotoxic threats. In Reviews of Environmental Contamination and Toxicology; Whitacre, D.M., Ed.; Springer: Cham, Switzerland, 2014.

34. Larue, C.; Castillo-Michel, H.; Sobanska, S.; Cecillon, L.; Bureau, S.; Barthes, V.; Ouerdane, L.; Carriere, M.; Sarret, G. Foliar exposure of the crop Lactuca sativa to silver nanoparticles: Evidence for internalization and changes in Ag speciation. J. Hazard Mater. 2014, 264, 98-106. [CrossRef] [PubMed]

35. Ghorbanpour, M.; Hatami, H. Changes in growth, antioxidant defense system and major essential oils constituents of Pelargonium graveolens plant exposed to nano-scale silver and thidiazuron. Indian J. Plant Physiol. 2015, 20, 116-123. [CrossRef]

36. Servin, A.; Elmer, W.; Mukherjee, A.; De La Torre-Roche, R.; Hamdi, H.; White, J.C.; Bindraban, P.; Dimkpa, C. A review of the use of engineered nanomaterials to suppress plant disease and enhance crop yield. J. Nanopart Res. 2015, 17, 1-21. [CrossRef]

37. Arruda, S.C.C.; Silva, A.L.D.; Galazzi, R.M.; Azevedo, R.A.; Arruda, M.A.Z. Nanoparticles applied to plant science: A review. Talanta 2015, 131, 693-705. [CrossRef]

38. Deng, Y.Q.; White, J.C.; Xing, B.S. Interactions between engineered nanomaterials and agricultural crops: Implications for food safety. J. Zhejiang Univ. Sci. A 2014, 15, 552-572. [CrossRef]

39. Rotkiewicz, D.; Konopka, I.; Tańska, M. Carotenoid and chlorophyll pigments in plant oils and their functions. Oil Plants 2010, XXIII, 561-579.

40. Ciecierska, M.; Obiedziński, M.W. Multi-ring aromatic hydrocarbon contamination in plant oils. Food. Sci. Technol. Qual. 2006, 2, 48-55.

41. Krygier, K.; Obiedziński, M.; Ratusz, K. Impact of bleeching processes on the quality of colf-pressed rapeseed oil. Oil Plants 1996, XVII, 455-459.

42. Krygier, K.; Wroniak, M.; Grześkiewicz, S.; Obiedziński, M. Study on the impact of damage seed content on the quality of cold-pressed rapeseed oil. Oil Plants 2000, XXI, 586-596.

43. Kozłowska, H.; Nowak, H.; Zadernowski, R. Rapeseed hulls fat characteristics. Eur. J. Lipid Sci. Technol 1988, 90, 216-219. [CrossRef]

44. Sionek, B. Cold-pressed oils. Rocz. PZH 1997, 48, 283-294.

45. Kachel-Jakubowska, M.; Sujak, A. Evaluation of physical properties of selected vegetable oils obtained by cold pressing. Acta Agrophysica 2016, 23, 583-592.

46. Priyadarshini, S.; Deepesh, B.; Zaidi, M.G.H.; Pardha-saradhi, P.; Khanna, P.K.; Arora, S. Silver nanoparticlemediated enhancement in growth and antioxidant status of Brassica juncea. Appl. Biochem. Biotechnol. 2012, 167, 2225-2233.

47. Koski, A.; Psomiadou, E.; Tsimidou, M.; Hopia, A.; Kefalas, P.; Wähälä, K.; Heinonen, M. Oxidative stability and minor constituents of virgin olive oil and cold-pressed rapeseed oil. Eur. Food Res. Technol. 2002, 214, 294-298. [CrossRef]

48. Wroniak, M.; Łukasik, D.; Maszewska, M. Comparison of the oxidative stability of cold-pressed and refined oils. Food. Sci. Technol. Qual. 2006, 1, 214-221.

49. Nunes, L.S.; Barbosa, J.T.; Fernandes, A.P.; Lemos, V.A.; dos Santos, W.N.; Korn, M.G.A.; Teixeira, L.S. Multi-element determination of $\mathrm{Cu}, \mathrm{Fe}, \mathrm{Ni}$ and $\mathrm{Zn}$ content in vegetable oils samples by high-resolution continuum source atomic absorption spectrometry and microemulsion sample preparation. Food Chem. 2011, 127, 780-783. [CrossRef]

50. Szyczewski, P.; Frankowski, M.; Zioła-Frankowska, A.; Siepak, J.; Szyczewski, T.; Piotrowsk, P. A comparative study of the content of heavy metals in oils: Linseed oil, rapeseed oil and soybean oil in technological production processes. Arch. Environ. Prot. 2016, 42, 37-40. [CrossRef]

51. Domka, F.; Cierpiszewski, R.; Kłopotek, A. Metal content in rapeseed oil occurring at various stages of production. Wybrane Problemy żywności 2010, 136-138. (in Polish).

52. Codex Alimentarius Commission Fats, Oils \& Related Products by Codex Alimentarius Commission-Codex Standard for Edible Fats and Oils not Covered by Individual Standards (CODEX STAN 19-1981, Rev. 2-1999). Available online: http://www.fao.org/3/y2774e/y2774e03.htm (accessed on 1 April 2019).

53. Cichosz, G.; Czeczot, H. Oxidative stability of edible fats-health consequences. Bromatol. Toxicol. Chem. 2011, XLIV, 50-60.

54. Wroniak, M.; Ptaszek, A.; Ratusz, K. Assessment of the conditions of expeller pressing on the quality and composition of rapeseed oils. Food. Sci. Technol. Qual. 2013, 1, 92-104. 
55. Maniak, B.; Zdybel, B.; Bogdanowicz, M.; Wójcik, J. Assessment of selected physicochemical properties of plant oils produced in the Lublin region. Agric. Eng. 2012, 3, 101-107.

56. Ismail, A.A.; Van de Voort, F.R.; Emo, G.; Sedman, J. Rapid quantitative determination of free fatty acids in fats and oils by Fourier transform infrared spectroscopy. J. Am. Oil Chem. Soc. 1993, 70, 335-341. [CrossRef]

57. Guillén, M.D.; Cabo, N. Fourier transform infrared spectra data versus peroxide and anisidine values to determine oxidative stability of edible oils. Food Chem. 2002, 77, 503-510. [CrossRef]

58. Dupuy, S.T.; Houser, C.R. Prominent expression of two forms of glutamate decarboxylase in the embryonic and early postnatal rat hippocampal formation. J. Neurosci. 1996, 16, 6919-6932. [CrossRef]

59. Rohman, A.; Che Man, Y.B. Analysis of cod-liver oil adulteration using Fourier transform infrared (FTIR) spectroscopy. J. Am. Oil Chem. Soc. 2009, 86, 1149. [CrossRef]

60. Cozzolino, D.; Smyth, H.E.; Gishen, M. Feasibility study on the use of visible and near-infrared spectroscopy together with chemometrics to discriminate between commercial white wines of different varietal origins. J. Agric. Food Chem. 2003, 51, 7703-7708. [CrossRef]

61. Singh, P.K.; Kumar, P.; Hussain, M.; Das, A.K.; Nayak, G.C. Synthesis and characterization of CuO nanoparticles using strong base electrolyte through electrochemical discharge process. Bull. Mater. Sci. 2016, 39, 469-478. [CrossRef]

(C) 2019 by the authors. Licensee MDPI, Basel, Switzerland. This article is an open access article distributed under the terms and conditions of the Creative Commons Attribution (CC BY) license (http://creativecommons.org/licenses/by/4.0/). 